\title{
Combined Oxygen and Glucose Deprivation in Cortical Cell Culture: Calcium-dependent and Calcium-independent Mechanisms of Neuronal Injury
}

\author{
Mark P. Goldberg and Dennis W. Choi \\ Department of Neurology, Washington University School of Medicine, St. Louis, Missouri 63110
}

\begin{abstract}
Murine neocortical cell cultures were transiently deprived of both oxygen and glucose, producing widespread neuronal swelling in less than $60 \mathrm{~min}$, followed by neuronal degeneration over the ensuing several hours, despite return to normal medium. Cultured glia ( $>95 \%$ astrocytes) were irreversibly injured only by oxygen-glucose deprivation exposures exceeding 4-6 hr.

Replacing either $\mathrm{Na}^{+}$or $\mathrm{Cl}^{-}$with impermeant ions blocked acute neuronal swelling but did not prevent delayed neuronal degeneration. While neuronal swelling and death were increased by removing $\mathrm{Ca}^{2+}$ from the exposure medium, combined removal of extracellular $\mathrm{Ca}^{2+}$ together with $\mathrm{Na}^{+}$or $\mathrm{Cl}^{-}$ substitution blocked both acute and delayed injury. If acute swelling was limited by a hyperosmolar medium, then neuronal loss depended on extracellular $\left[\mathrm{Ca}^{2+}\right]$.
\end{abstract}

Oxygen-glucose deprivation was associated with a large increase in extracellular glutamate concentration. Both early swelling and later neuronal degeneration were blocked by addition of NMDA receptor antagonists to the exposure medium but not by the AMPA/kainate receptor antagonist 6-cyano-7-dinitroquinoxaline-2,3-dione (CNQX), dihydropyridines nifedipine or nimodipine, or TTX. Oxygen-glucose deprivation induced substantial neuronal uptake of tracer ${ }^{45} \mathrm{Ca}^{2+}$ from the exposure medium that was reduced by NMDA receptor antagonists and closely paralleled the degree of subsequent neuronal loss.

These observations suggest the presence of two distinct components of hypoxic injury, each involving NMDA receptor activation and each capable of leading to neuronal death. Acute swelling is mediated by influx of $\mathrm{Na}^{+}, \mathrm{Cl}^{-}$, and water, and is enhanced by removal of extracellular $\mathrm{Ca}^{2+}$. Delayed neuronal degeneration depends on the presence of extracellular $\mathrm{Ca}^{2+}$ and correlates closely with cellular uptake of ${ }^{45} \mathrm{Ca}^{2+}$.

[Key words: hypoxia, ischemia, neurons, glia, calcium, cell culture, glutamate receptors, NMDA receptors]

\footnotetext{
Received Aug. 7, 1992; revised Feb. 11, 1993; accepted Feb. 24, 1993.

We thank M. C. Kurth for assistance with the ${ }^{45} \mathrm{Ca}^{2+}$ uptake assays, and $\mathrm{K}$. Rose and M. C. Bateman for expert cell culture assistance. This work was supported by a Dana Foundation fellowship and Clinician Investigator Development Award NS01543 to M.P.G. and by NIH Grant NS26907 to D.W.C.

Correspondence should be addressed to Mark P. Goldberg, Department of Neurology, Box 8111 , Washington University School of Medicine, St. Louis, MO 63110.

Copyright $\odot 1993$ Society for Neuroscience $0270-6474 / 93 / 133510-15 \$ 05.00 / 0$
}

The brain requires a continuous supply of oxygen and glucose to maintain normal function and viability. Loss of this supply for only a few minutes can trigger a cascade of events leading to neuronal death; if the deprivation is sustained, glial and endothelial cells also succumb. Recent evidence has suggested that the toxic overactivation of neuronal NMDA receptors may contribute to hypoxic-ischemic neuronal injury, at least in focal ischemia (Meldrum, 1985; Rothman and Olney, 1986; Choi, 1988). Implication of NMDA receptors in hypoxic-ischemic neuronal injury provides an attractive link to previous studies suggesting that this injury may be due to calcium overload (Siesjo and Bengtsson, 1989), as the rapidly triggered neurotoxic injury induced by NMDA receptor overstimulation may be initiated by excessive calcium influx through NMDA receptorgated channels (MacDermott et al., 1986; Choi, 1987). However the idea that extracellular $\mathrm{Ca}^{2+}$ plays a central role in hypoxic neuronal injury has been challenged by in vitro observations that removal of extracellular $\mathrm{Ca}^{2+}$ fails to block neuronal damage in cell culture (Goldberg et al., 1986; Nedergaard, 1991), hippocampal slice (Olsen et al., 1987; Raley-Susman and Lipton, 1990), or isolated retina (Ames and Nesbett, 1983) preparations.

We have found that the degeneration of cultured cortical neurons induced by deprivation of either oxygen (Goldberg et al., 1987) or glucose (Monyer et al., 1989) alone could be blocked by NMDA antagonists. It would be of interest to examine the role of extracellular $\mathrm{Ca}^{2+}$ in these forms of neuronal degeneration, but these cultures do not tolerate $\mathrm{Ca}^{2+}$ removal for the several hours required to induce widespread neuronal injury in each case. Therefore, we turned to the injury induced by combined oxygen and glucose deprivation, an insult that more closely approximates the conditions associated with cerebral ischemia in vivo, and induces injury rapidly enough to permit manipulation of extracellular ionic conditions. Specifically, we sought support for the hypothesis that the neuronal degeneration induced by this insult, like that induced by exogenously added glutamate, would be due in large part to $\mathrm{Ca}^{2+}$ overload triggered by the excess influx of extracellular $\mathrm{Ca}^{21}$ through NMDA receptor-gated channels.

Abstracts have appeared previously (Goldberg et al., 1988a, 1989).

\section{Materials and Methods}

Cell cultures. Mixed neocortical cultures, containing both neurons and glia, were prepared from fetal mice at $14-17 \mathrm{~d}$ gestation, generally as previously described (Choi et al., 1987, Rose et al., 1993). Dissociated cells were plated at 2.75-3.75 hemispheres per 24-well $(15 \mathrm{~mm})$ culture 
vessel (Falcon Primaria) in a plating medium consisting of Eagle's minimal essential medium (MEM; Earle's salts, supplied glutamine-free) supplemented with glucose (final concentration, $20 \mathrm{~mm}$ ), $2 \mathrm{~mm}$ glutamine, $10 \%$ fetal bovine serum, and $10 \%$ horse serum. When the glial monolayer reached confluency (7-10 d in vitro), non-neuronal cell division was arrested by $1-3 \mathrm{~d}$ exposure to $10 \mu \mathrm{M}$ cytosine arabinoside. Cultures were subsequently fed twice weekly with a medium identical to plating medium, except that it contained $10 \%$ horse serum and no fetal serum. Alternatively, cells were plated onto a previously established glial monolayer (see below) in plating medium containing $5 \%$ fetal bovine serum and no horse serum, and cytosine arabinoside was added 4-8 d after plating. Cultures plated on glia were more consistent in cell density and neuronal survival; however, these two methods yielded comparable experimental results. Cultures were maintained at $37^{\circ} \mathrm{C}$ in a humidified incubator containing $5 \% \mathrm{CO}_{2}$ and atmospheric oxygen. Cultures were used for experiments between 14 and $18 \mathrm{~d}$ in vitro.

Glial cultures were prepared from neocortices of postnatal (day 1-3) mice (McCarthy and de Vellis, 1980) and plated at 0.5-2.0 hemispheres per 24 -well vessel, in plating medium as described above $(10 \%$ horse serum and $10 \%$ fetal bovine serum). After 2 weeks in vitro, cultures were fed weekly with the same medium as for mixed cultures. Glial cultures were used for expeirments after $2-4$ weeks in vitro. Glial cells for feeder cultures were prepared with the following modifications: plating density was reduced to $0.25-0.5$ hemispheres per 24-well vessel, the medium was supplemented with $10 \mathrm{ng} / \mathrm{ml}$ epidermal growth factor (Sig$\mathrm{ma}$ ), and cultures were not fed prior to plating mixed cultures at 2-3 weeks in vitro.

Oxygen-glucose deprivation. Cultures were transferred to an anaerobic chamber (Forma Scientific) containing a gas mixture of $5 \% \mathrm{CO}_{2}, 10 \%$ $\mathrm{H}_{2}, 85 \% \mathrm{~N}_{2}$. The culture medium was replaced by thorough exchange (effective dilution $<1: 1000$ ) with deoxygenated, glucose-free Earle's balanced salt solution ( $\mathrm{BSS}_{0}$ ) with the following ionic composition (in mM): $\mathrm{Na}^{+}, 143.6 ; \mathrm{K}^{+}, 5.4 ; \mathrm{Ca}^{2+}, 1.8 ; \mathrm{Mg}^{2+}, 0.8 ; \mathrm{Cl}^{-}, 125.3 ; \mathrm{HCO}_{3}^{-}$, $26.2 ; \mathrm{H}_{2} \mathrm{SO}_{4}^{2-}, 1.0 ; \mathrm{SO}_{4}^{2-}, 0.8$; and phenol red, $10 \mathrm{mg} /$ liter. Cultures were then placed in a humidified $37^{\circ} \mathrm{C}$ incubator within the anaerobic chamber. Oxygen-glucose deprivation was terminated by replacing the exposure medium with oxygenated MEM containing $5.5 \mathrm{mM}$ glucose and $2 \mathrm{~mm}$ L-glutamine (Sigma; freshly added from concentrated solution stored in aliquots at $-70^{\circ} \mathrm{C}$ ), and cultures were returned to the normoxic incubator.

Prior to use, $\mathrm{BSS}_{0}$ was equilibrated with the anaerobic gas mixture by bubbling for 3-5 min, adjusted to $\mathrm{pH} 7.4$ if necessary, and heated to $37^{\circ} \mathrm{C}$. Oxygen content of the chamber atmosphere and exposure medium $(<2 \mathrm{~mm} \mathrm{Hg}$ ) were monitored with an oxygen-sensitive electrode (Microelectrodes, Inc.). In some experiments, oxygen-glucose deprivation injury was compared with injury following isolated oxygen or glucose deprivation. Glucose deprivation was accomplished in the normoxic incubator using $\mathrm{BSS}_{0}$ equilibrated with $5 \% \mathrm{CO}_{2} / 95 \%$ air and was terminated by adding glucose to bring the final concentration to $5.5 \mathrm{~mm}$. Oxygen deprivation was performed using deoxygenated BSS initially containing $2.0,5.5$, or $20.0 \mathrm{~mm}$ glucose. To ensure that medium glucose remained close to 2.0 or $5.5 \mathrm{~mm}$, the exposure medium was sampled at $4 \mathrm{hr}$ intervals and glucose was added as required. Exposure was terminated by bringing final glucose to at least $5.5 \mathrm{~mm}$ and returning the cultures to the normoxic incubator. Cell injury was assessed $1 \mathrm{~d}$ later. When the initial glucose concentration was $20 \mathrm{~mm}$, no medium glucose supplementation was provided during hypoxic exposure. Glial cultures were exposed to similar conditions, except that, for oxygendeprivation experiments (glucose, 5. $5 \mathrm{~mm}$ ), medium glucose was sampled and corrected every $24 \mathrm{hr}$, and injury was assessed each day.

Immunohistochemistry. Cultures were fixed with $4 \%$ paraformaldehyde in Tris-buffered saline (TBS), permeabilized with $0.25 \%$ Triton $\mathrm{X}-100$, and stained with cresyl violet or processed for immunohistochemistry. Cells were incubated successively in the following reagents: $10 \%$ normal goat serum (NGS); polyclonal rabbit antibody (Incstar) directed against neuron-specific enolase (NSE; diluted from supplied stock 1:10 in TBS with $2 \%$ NGS) or glial fibrillary acidic protein (GFAP; diluted $1: 3$ in TBS with $2 \%$ NGS); biotinylated goat anti-rahbit secondary antibody (1:100 in TBS with $2 \%$ NGS; Vector); avidin-biotinperoxidase reagent (Vector); and $0.05 \%$ diaminobenzidine tetrahydrochloride $/ 0.01 \%$ hydrogen peroxide. Nonspecific staining was assessed by substituting primary antibody with normal rabbit serum diluted $1: 500$ in TBS.

Assessment of neuronal and glia injury. Cultures were observed under phase-contrast optics at 200-400×, immediately after and at least $1 \mathrm{~d}$ following oxygen-glucose deprivation. Cell viability was assessed in some experiments under bright-field optics after $5 \mathrm{~min}$ incubation with $0.4 \%$ trypan blue, which stains nonviable cells.

Ccll injury was quantitatively assessed by measuring lactate dehydrogenase $(\mathbf{L D H})$, released from damaged cells into the extracellular medium $1 \mathrm{~d}$ after oxygen-glucose deprivation (Koh and Choi, 1987). A small amount of LDH was present in the media of cultures exposed to the same wash conditions in oxygenated BSS containing $5.5 \mathrm{~mm}$ glucose; this background LDH release was determined in sister cultures for each experiment and subtracted from values obtained in treated cultures. Previous experiments have demonstrated that specific LDH release following glutamate exposure or hypoxia correlates linearly with the degree of loss assessed by cell counts using morphological criteria (Goldberg et al., 1987; Koh and Choi, 1987). In mixed cultures exposed to energy-depleted conditions, most (or all) of this LDH signal reflected neuronal injury: these exposures were not sufficiently prolonged to destroy significant numbers of glial cells (see Results). Glial injury was assessed in scparatc cxpcriments by measuring $\mathrm{LDH}$ release from pure glial cultures. All LDH measurements presented here represent at least three similar experiments.

Assessment of neuronal swelling. Cell areas were determined using an image analysis system (Universal Imaging) by tracing neuronal outlines from phase-contrast videomicrographs $(400 \times$, Javelin CCD camera) that were taken immediately following oxygen-glucose deprivation, digitized, and stored on a microcomputer disk.

High-performance liquid chromatography (HPLC). Amino acid accumulation in the extracellular medium was measured by reversedphase HPLC with $O$-phthaldialdehyde precolumn derivitization and fluorescence detection (Lindroth and Mopper, 1979). Exposure medium was sampled during oxygen-glucose deprivation and stored at $-20^{\circ} \mathrm{C}$. Aliquots $(30 \mu \mathrm{l})$ were mixed with $30 \mu \mathrm{l} o$-phthaldialdehyde/2-mercaptoethanol reagent (Sigma) and injected onto a $3.9 \times 150 \mathrm{~mm} \mathrm{C18}$ analytical column (Resolve, Waters). Glutamate and aspartate were separated from each other and from other amino acids using a rapid gradient elution (flow rate, $1.5 \mathrm{ml})$ : solvent $\mathrm{A}(0.1 \mathrm{M}$ potassium acetate, pH 7.4:methanol, 80:20) to solvent $\mathrm{B}$ (potassium acetate : methanol, 20: 80 ) over $3 \mathrm{~min}$. $O$-phthaldialdehyde derivatives of glutamate and aspartate were identified by their retention times, and concentrations were quantified by peak area comparisons to a standard solution containing 40 amino acids (Sigma).

${ }^{45} \mathrm{Ca}^{2+}$ accumulation. Cells were deprived of oxygen and glucose as described above, with inclusion of ${ }^{45} \mathrm{Ca}^{2+}$ (New England Nuclear; final activity, $0.5-1.0 \mu \mathrm{Ci} / \mathrm{ml}$ ) in the exposure medium (Hartley et al., 1993). Oxygen-glucose deprivation was terminated by thoroughly replacing radiolabeled medium with unlabeled oxygenated MEM (effective dilution $<1 / 20,000$ ), so that only intracellularly incorporated ${ }^{45} \mathrm{Ca}^{2+}$ remained. To measure ${ }^{45} \mathrm{Ca}^{2+}$ uptake and subsequent cell death in the same culture, cultures were returned to the incubator for $24 \mathrm{hr}$, and then a small aliquot of the extracellular medium was sampled for LDH measurement, the cells were lysed by addition of $0.2 \%$ sodium dodecyl sulfate to the medium, and the resulting solution was added to scintillation solution for counting of beta emissions.

Reagents. Experimental drugs were dissolved in $\mathrm{BSS}_{0}$ at $10-100 \times$ final concentration. Immediately before use, the stock solutions were deoxygenated by bubbling with the anaerobic gas mixture and diluted in the appropriate oxygen-glucose deprivation exposure medium ( $\left.\mathrm{BSS}_{0}\right)$. All drugs were removed at the conclusion of oxygen-glucose deprivation. Nifedipine and nimodipine were first dissolved in dimethyl sulfoxide at 100-1000 ; control experiments showed that this vehicle alone did not alter uxygen-glucose deprivation injury. Reagents were obtained as follows: D-amino-5-phosphonovalerate (D-APV; Tocris Neuramin), 7-chlorokynurenic acid (Tocris), 6-cyano-7-nitroquinoxaline-2,3-dione (CNQX, Tocris, or CRB), MK-801 (Merck, Sharp \& Dohme), CGS19755 (Ciba-Geigy), and dextrorphan (Hoffmann-La Roche). Most other reagents were obtained from Sigma.

\section{Results}

\section{Morphological changes}

Neuronal cell bodies in mixed cortical cell cultures are readily distinguished from the underlying glial monolayer using either phase-contrast optics in unfixed cells or bright-field optics after fixation and Nissl staining (Choi et al., 1987). In mature cultures ( $>10 \mathrm{~d}$ in vitro), immunocytochemical staining using antibodies 

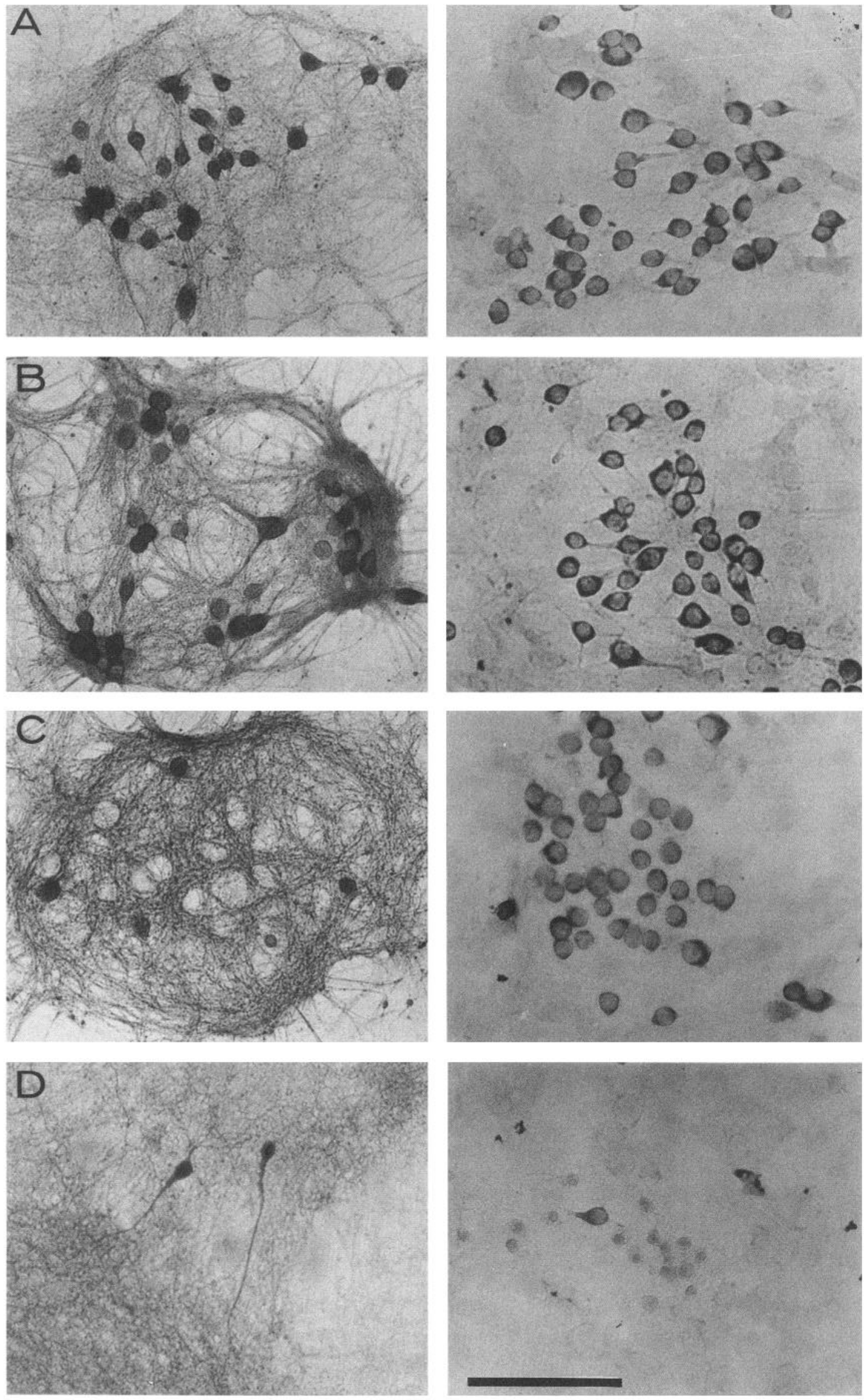
directed against NSE additionally revealed the presence of a dense network of neuronal processes (Fig. 1). Cultures exposed to oxygen-glucose deprivation for $50 \mathrm{~min}$, fixed immediately, and stained for Nissl substance or NSE showed little early change in gross neuronal morphology. Although cultures were then returned to normal oxygen- and glucose-containing MEM, neuronal morphology deteriorated in the next 1-2 $\mathrm{hr}$, with progressive ncuronal swclling and loss of NSE and Nissl staining (Fig. 1). The neurite layer developed a vacuolar appearance. By the following day, most neurons were replaced by debris, with nuclear remnants stained with trypan blue (not shown). In contrast, brief deprivation of oxygen and glucose produced no gross morphological injury in the underlying glial monolayer, and glial cells excluded trypan blue.

In unfixed cultures viewed under phase-contrast optics, neuronal cell bodies immediately following oxygen-glucose deprivation were markedly swollen with phase-dark nuclei and loss of phase-bright contours (see Fig. 6B). Mean neuronal area increased from $188 \pm 59 \mu \mathrm{m}^{2}$ in cultures exposed to normoxic wash conditions to $320 \pm 114 \mu \mathrm{m}^{2}$ in sister cultures deprived of oxygen and glucose for $45 \mathrm{~min}$ (mean $\pm \mathrm{SD}, n=100$ neurons from four cultures in each condition, $p<0.01$ ). Observation with an inverted microscope and closed-circuit video camera placed in the anaerobic chamber rcvealed that these changes occurred even before replacement of cells in normal MEM, and therefore were not a consequence of reoxygenation (i.e., "reperfusion injury").

\section{Time course of neuronal injury}

During acute oxygen-glucose deprivation exposure (up to 70 min), LDH in the medium did not exceed the baseline amount found in normoxic wash controls (not shown). Substantial LDH release first appeared within $2 \mathrm{hr}$ of the conclusion of oxygenglucose deprivation, and was maximal by $12-16 \mathrm{hr}$ later. The LDH signal measured $1 \mathrm{~d}$ after exposure reflected the degree of overall neuronal injury assessed morphologically (Goldberg et al., 1987). Using LDH release measured 20-28 hr after exposure as a quantitative index, we examined the relationship between the duration of exposure to oxygen-glucose deprivation and resulting injury (Fig. 2).

Exposures shorter than 30 min produced little neuronal loss by the next day. Exposure durations between 40 and $60 \mathrm{~min}$ produced increasing intermediate neuronal injury, with maximal injury and LDH release observed after 70 min exposure. This maximal injury consisted of the death of $>90 \%$ of neurons, as assessed by phase-contrast observation and trypan blue dye exclusion. The exposure duration required for half-maximal neuronal injury (typically $40-50 \mathrm{~min}$ ) varied between cultures of different platings but was generally consistent among sister cultures derived from a single plating. Therefore, critical comparisons were always made between sister cultures exposed to oxygen-glucose deprivation on the same day.

We compared the time course of oxygen-glucose deprivation neuronal injury to that produced by removal of oxygen (Goldberg et al., 1987) or glucose (Monyer et al., 1989) alone (Fig. 2). As previously noted, these latter two insults wcrc capable of

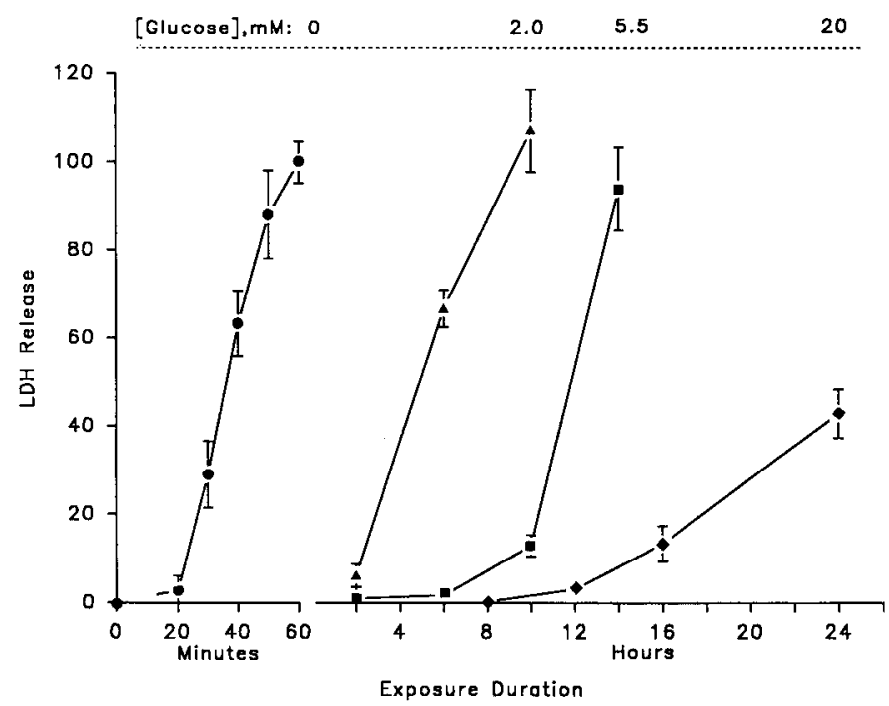

Figure 2. Effect of hypoxic exposure duration on subsequent neuronal loss: role of glucose concentration. Sister cultures were transiently placed in oxygen-free medium with the indicated initial glucose concentration, for the exposure duration shown, and neuronal death was assessed by measurement of LDH in the medium $1 \mathrm{~d}$ later. Exposure was terminated by adding glucose, if necessary, to bring medium glucose to $\geq 5.5 \mathrm{~mm}$ and by returning cultures to the normoxic incubator. To assure stable glucose levels during longer hypoxic exposures, medium glucose was sampled periodically and concentrated glucose was added to bring the medium concentration to the desired range (actual glucose concentrations were 1.1-2.0, 4.4-5.0, 15.4-20.0 mM, respectively). Values represent mean LDH \pm SEM $(n=3-4)$, scaled to the mean LDH present in cultures deprived of oxygen and glucose for $60 \mathrm{~min}(=100)$. Note expanded time scale in first $60 \mathrm{~min}$.

producing widespread neuronal degeneration only after several hours of continuous exposure. The exposure duration required for a pure hypoxic insult to induce comparable neuronal loss depended on glucose concentration over a wide range: halfmaximal injury occurred after 4-8 hr with glucose maintained near $2.0 \mathrm{~mm}, 8-14 \mathrm{hr}$ with glucose maintained near $5.5 \mathrm{~mm}$, and $>24 \mathrm{hr}$ with glucose maintained near $20 \mathrm{~mm}$. Isolated glucose deprivation in atmospheric oxygen produced half-maximal neuronal loss after 6-8 hr, with maximal neuronal damage following 10-12 hr exposures (not shown). Despite these temporal differences, maximal LDH release was similar in each condition except for hypoxic exposure in $20 \mathrm{~mm}$ glucose, which caused only partial neuronal loss at the longest exposure duration tested $(24 \mathrm{hr})$. These time courses are somewhat longer than we have previously reported for isolated oxygen or glucose deprivation, due likely, in the case of oxygen deprivation, to maintenance of medium glucose near starting levels and, in the case of glucose deprivation, to omission of amino acids from the exposure medium (Goldberg et al., 1988b; Monyer and Choi, 1990).

\section{Glial injury}

In previous experiments, glial cells in mixed cultures were not visibly injured by oxygen or glucose deprivation sufficient to destroy virtually all of the neurons (Goldberg et al., 1987; Mon-

Figure 1. Altered neuronal morphology produced by transient oxygen-glucose deprivation: bright-field photomicrographs of mixed neuronal and glial cerebrocortical cultures before exposure $(A)$, immediately after 50 min oxygen-glucose deprivation $(B), 2 \mathrm{hr}$ after deprivation $(C)$, and $1 \mathrm{~d}$ after deprivation $(D)$. Left panels show immunoperoxidase staining for NSE; right panels show Nissl stain (cresyl violet). At $2 \mathrm{hr}$, swollen neuronal cell bodies have lost NSE reactivity. By the following day, only scattered intact neurons are seen on a background of Nissl or NSE-positive debris. Scale bar, $100 \mu \mathrm{m}$. 

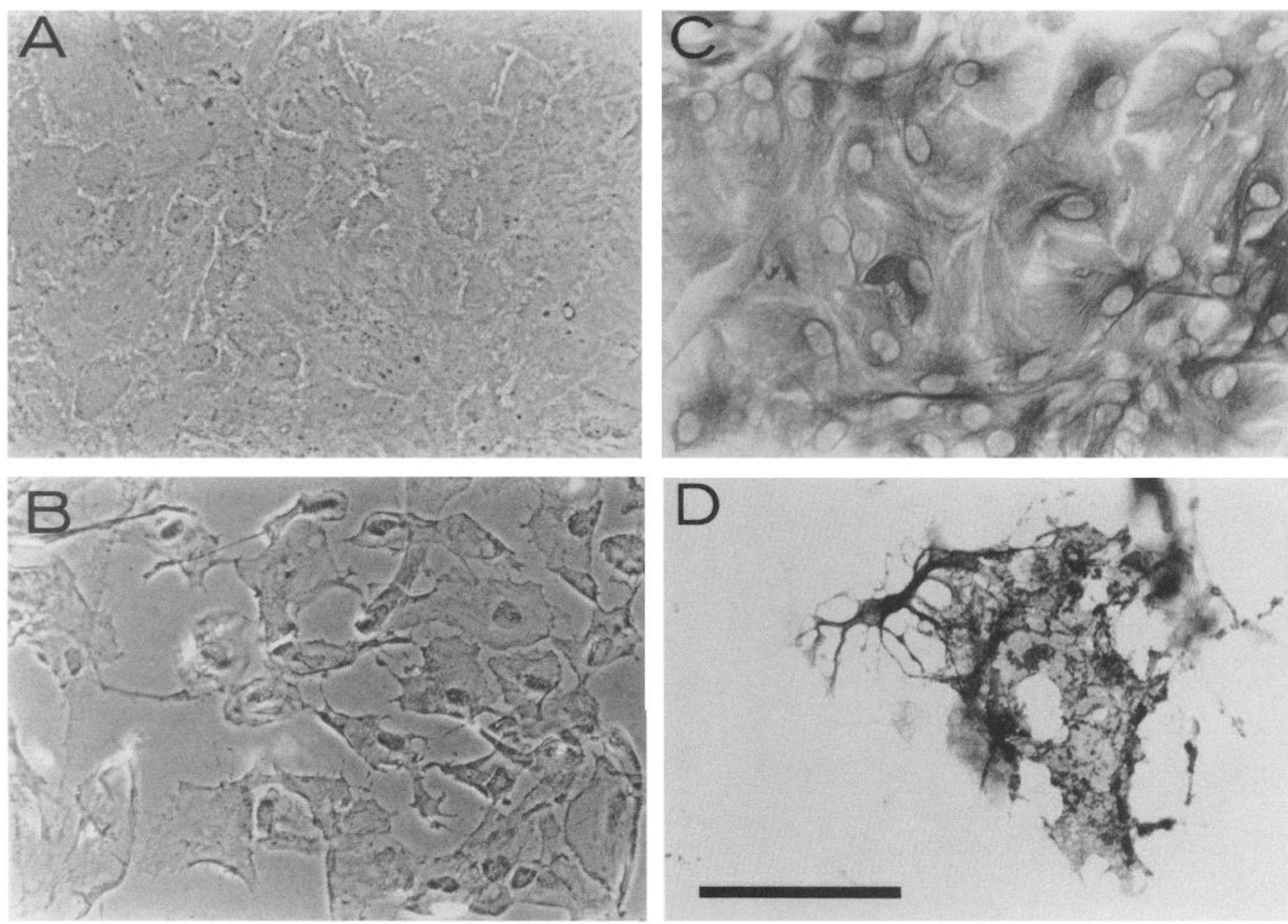

Figure 3. Morphology of glial injury following prolonged oxygen-glucose deprivation. Phase-contrast photomicrographs show representative fields from sister glial cultures ( $>95 \%$ astrocytes) before $(A)$ and $4 \mathrm{hr}$ after $(B) 6 \mathrm{hr}$ oxygen-glucose deprivation. Bright-field photomicrographs show fields after fixation and immunoperoxidase staining for GFAP, before $(C)$ and $1 \mathrm{~d}$ after $(D) 6 \mathrm{hr}$ oxygen-glucose deprivation. Following exposure, astrocyte cytoplasm was contracted and many cells detached from the culture surface. $D$ shows one intact astrocyte surrounded by GFAP-reactive debris. Scale bar, $100 \mu \mathrm{m}$.

yer et al., 1989). Similarly, combined oxygen-glucose deprivation for 60 min produced widespread loss of neurons but not glia (Figs. 1, 3). To examine glial vulnerability to more prolonged insults, we prepared astrocyte cultures consisting of a confluent monolayer of flat, polygonal cells (Fig. $3 A$ ), more than $95 \%$ of which stained immunohistochemically for GFAP (Fig. 3C). Oxygen-glucose deprivation for less than $4 \mathrm{hr}$ produced neither visible injury nor measurable LDH release, whereas exposure durations in the range of 4-12 hr yielded graded glial injury. This appeared under phase-contrast optics initially as a contraction of astrocyte cytoplasm and darkening around the nucleus (Fig. 3B). With exposures longer than $6-8 \mathrm{hr}$, increasing numbers of glia failed to exclude trypan blue dye and many cells subsequently detached from the cell culture surface (Fig. $3 B, D$ ). Similar astrocyte injury could be produced by prolonged glucose deprivation $(>36 \mathrm{hr})$ in the presence of atmospheric oxygen (Fig. 4). In contrast, oxygen deprivation when glucose was maintained near $5.5 \mathrm{~mm}$ caused little glial injury even after $5 \mathrm{~d}$ continuous exposure. Hypoxic exposures longer than $5 \mathrm{~d}$ did produce substantial glial loss (two experiments, not shown); however, in these cultures the $\mathrm{pH}$ of the bathing medium fell below 6.5 , alone sufficient to cause glial death in our system (Giffard et al., 1990b).

\section{Glutamate release}

Glutamate concentration in normoxic culture medium was approximately $0.1 \mu \mathrm{M}$, near the detection limit for our HPLC system, and did not rise over $60 \mathrm{~min}$. Extracellular glutamate concentration remained low during oxygen-glucose deprivation exposure briefer than $30 \mathrm{~min}$, but with longer exposures glutamate rose substantially, reaching levels of 1.5-2.5 $\mu \mathrm{M}$ (four experiments) after $60 \mathrm{~min}$ (Fig. 5).

\section{Pharmacology of oxygen-glucose deprivation injury}

Oxygen-glucose deprivation-induced neuronal swelling (Figs. $6,7 A$ ) and subsequent death (Figs. $6,7 B$ ) were blocked by inclusion in the exposure medium of several selective NMDA antagonists, including the noncompetitive antagonists MK-801 (10-100 $\mu \mathrm{M}$; Fig. 6) and dextrorphan $(100 \mu \mathrm{M})$; the competitive antagonists D-APV $(300-1000 \mu \mathrm{M})$, CPP $(100 \mu \mathrm{M})$, and CGS $19755(100 \mu \mathrm{M})$; and the NMDA receptor-associated glycine antagonist 7-chlorokynurenate (300 $\mu \mathrm{M})$. Neurons protected by inclusion of NMDA antagonists excluded trypan blue and remained morphologically intact (by phase-contrast, Nissl, or antiNSE staining) for at least $2 \mathrm{~d}$ after exposure.

The effect of NMDA antagonists was concentration depen- 


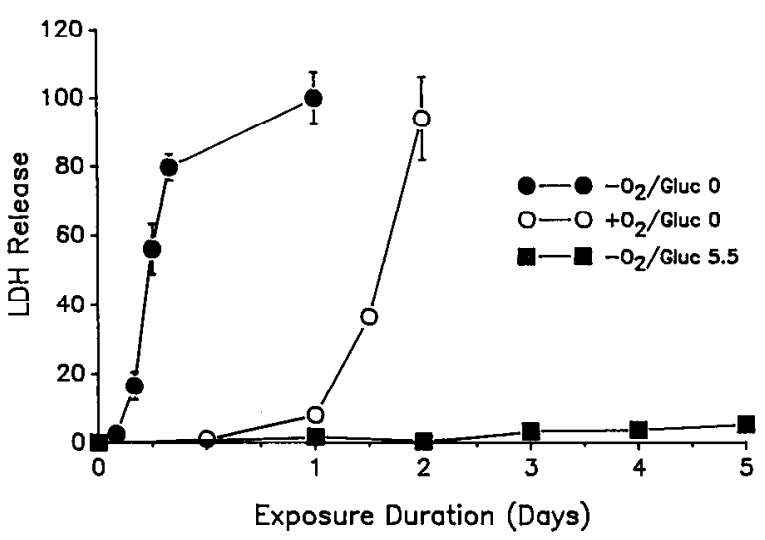

Figure 4. Time dose-response of glial injury following oxygen deprivation, glucose deprivation, or combined insult. Sister glial cultures were exposed to medium with $\left(+\mathrm{O}_{2}\right)$ or without oxygen $\left(-\mathrm{O}_{2}\right)$, and with the glucose concentration ( 0 or $5 \mathrm{~mm}$ ) indicated. Cell injury was assessed by measurement of LDH in the medium $1 \mathrm{~d}$ following exposure, except in oxygen deprivation, when it was sampled daily. In the case of oxygen deprivation, medium glucose was sampled daily and supplemented as required to return to $5.5 \mathrm{~mm}$. In each case, exposure was terminated by bringing glucose to $5.5 \mathrm{~mm}$ (if necessary), and returning cultures to the normoxic incubator. Note expanded time scale in first $24 \mathrm{hr}$.

dent, with maximal protection noted for dextrorphan around $100 \mu \mathrm{M}$ (Fig. 8A), D-APV at $1 \mathrm{mM}$ (see Fig. 13D), and MK-801 at $10 \mu \mathrm{M}$ (not shown). Partial protection was observed even when the NMDA antagonist was added immediately following submaximal oxygen-glucose deprivation (Fig. 8B); however, this rescue effect was no longer seen if administration was delayed beyond 15-30 min following exposure, or if the initial exposure was extended beyond 50-60 min. Neuronal injury was greatly enhanced by reducing $\mathrm{Mg}^{2+}$ in the exposure medium (normally $0.8 \mathrm{~mm}$ ) (Fig. 8C).

Addition of the AMPA/kainate antagonist CNQX $(10 \mu \mathrm{M})$ did not reduce neuronal swelling (Fig. $7 A$ ) or death (Fig. $7 B$ ). CNQX partially attenuated neuronal loss when added at concentrations $>30 \mu \mathrm{M}$ (three experiments, not shown); however, at these concentrations CNQX nonselectively blocks NMDA receptor-mediated injury in our system, presumably by interacting with the glycine site (Koh and Choi, 1991). We found no reduction of neuronal swelling (Fig. $7 A$ ) or loss (Fig. $7 B$ ) with even high concentrations of the voltage-gated $\mathrm{Ca}^{2+} \mathrm{L}$-channel antagonists nifedipine $(10-100 \mu \mathrm{M})$ or nimodipine $(30 \mu \mathrm{M})$, or the voltage-sensitive $\mathrm{Na}^{+}$channel blocker TTX $(10 \mu \mathrm{M})$. [Nifedipine at $100 \mu \mathrm{M}$ enhanced neuronal injury in some experiments (Fig. 7A).] None of the tested agents attenuated cell death in glial cultures following $6 \mathrm{hr}$ oxygen-glucose deprivation exposure (Fig. 8D).

\section{Effect of $\mathrm{Ca}^{2+}$ removal}

The rapidity with which combined oxygen and glucose deprivation induced neuronal injury allowed us to examine the effects of altering the ionic composition of $\mathrm{BSS}_{0}$ during the exposure period. At the conclusion of oxygen-glucose deprivation, all culturcs were returned to MEM with normal ionic composition. Removal of $\mathrm{Ca}^{2+}$ from the $\mathrm{BSS}_{0}$ exposure solution did not reduce subsequent neuronal degeneration (Figs. $9 A$, bottom; $10 B$ ). Under conditions of submaximal injury, $\mathrm{Ca}^{2+}$ removal actually increased overall neuronal loss (Fig. 10B). Neuronal injury in $\mathrm{BSS}_{0}$ with no added $\mathrm{Ca}^{2+}$ differed from that seen under normal ionic conditions in that acute neuronal swelling was greatly en-

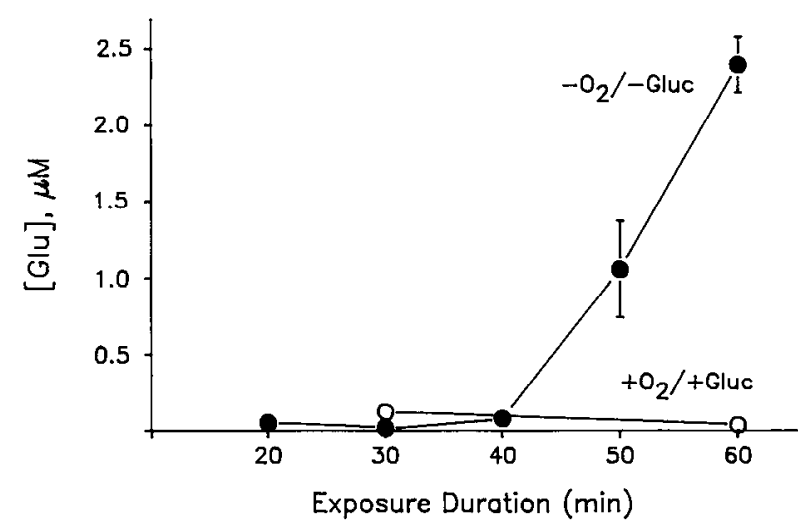

Figure 5. Extracellular glutamate increases during oxygen-glucose deprivation. Sister cultures were exposed to normoxic wash conditions $\left(+\mathrm{O}_{2} /+G / u c\right)$ or to combined oxygen-glucose deprivation $\left(-\mathrm{O}_{2} /-G l u c\right)$, and the medium was sampled at the times indicated. Values represent mean glutamate \pm SEM $(n=3$ or 4$)$ determined by HPLC.

hanced (Figs. $9 A$, top; $10 A$ ) and substantial LDH efflux occurred even before the conclusion of oxygen-glucose deprivation (Fig. $10 \mathrm{~B}$, crosshatched bar). We considered the possibility that neuronal injury in nominally $\mathrm{Ca}^{2+}$-free medium was due to the presence of residual medium $\mathrm{Ca}^{2+}$. However, addition of $100-$ $500 \mu \mathrm{M}$ EGTA further increased injury (four experiments); therefore, we did not include EGTA in subsequent media. EGTA was not toxic at these concentrations under normoxic conditions.

We examined the pharmacology of the enhanced neuronal loss seen following oxygen-glucose deprivation in medium with no added $\mathrm{Ca}^{2+}$. Because this form of injury is unlikely directly to involve transmembrane $\mathrm{Ca}^{2+}$ entry during exposure, one prediction might be that mechanisms other than NMD $\Lambda$ receptor activation play a role. In fact, the pharmacology of injury was similar to that in normal ionic exposures: NMDA antagonists attenuated neuronal damage; CNQX, nifedipine, and TTX did not prevent either acute neuronal swelling (not shown) or delayed death (Fig. 11).

\section{Effect of sodium or chloride substitution}

A markedly altered pattern of neuronal injury was seen in cultures deprived of oxygen and glucose in low- $\mathrm{Na}^{+}$medium (residual $\mathrm{Na}^{+}, 27.2 \mathrm{~mm} ; \mathrm{NaCl}$ replaced by choline chloride, $>20$ experiments; or by $\mathrm{N}$-methyl-D-glucamine, three experiments). Acute neuronal swelling immediately following exposure was greatly attenuated, with many neurons maintaining normal phase-bright contours and cell area (Figs. $9 B$, top; $10 A$ ). However, within $1 \mathrm{hr}$ of returning cells to normal MEM, neuronal outlines became progressively more granular, and by the following day, neuronal degeneration was as widespread as in sister cultures exposed to oxygen-glucose deprivation in BSS $_{0}$ (Figs. $9 B$, bottom; $10 B)$. The same sequence of events was observed in low- $\mathrm{Cl}^{-} \mathrm{BSS}_{0}$, in which $\mathrm{NaCl}$ was replaced by sodium isethionate (residual $\mathrm{Cl}^{-}, 3.6 \mathrm{~mm}$ ). Low $\mathrm{Cl}^{-}$exposure resulted in even better preservation of acute neuronal morphology than low $\mathrm{Na}^{+}$but also did not block late degeneration. Neither $\mathrm{Na}^{+}$ nor $\mathrm{Cl}^{-}$substitution significantly attenuated neuronal loss assessed by late LDH release (Fig. 10B). However, both acute hypoxic swelling and delayed degeneration were substantially attenuated when $\mathrm{Na}^{+}$or $\mathrm{Cl}^{-}$substitution was combined with $\mathrm{Ca}^{2+}$ removal (Figs. 9, 10).

The most likely explanation for the ability of $\mathrm{Na}^{+}$or $\mathrm{Cl}^{-}$ 

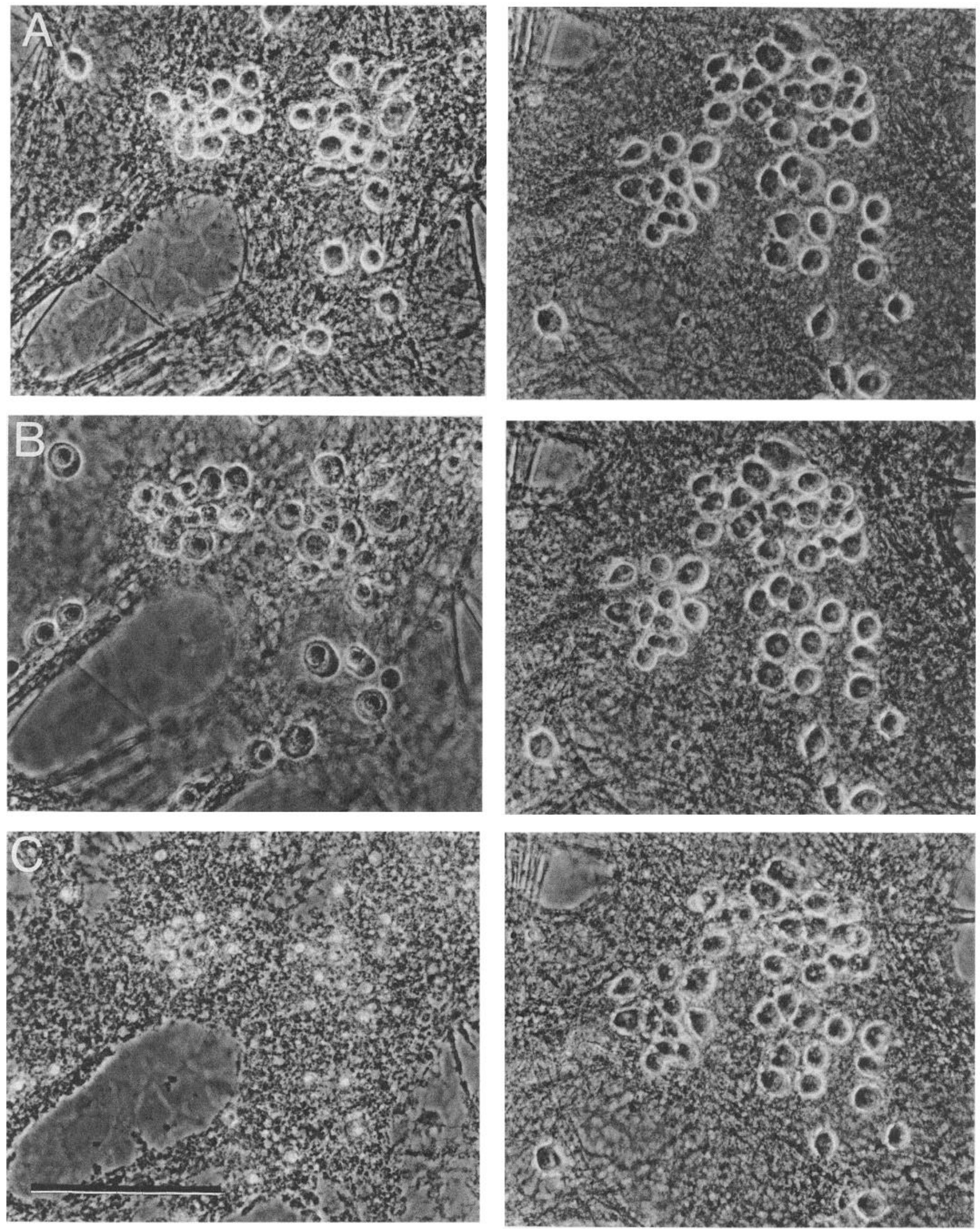
substitution to reduce the acute neuronal swelling induced by oxygen-glucose deprivation is that these substitutions limit the movement of $\mathrm{Na}^{+}, \mathrm{Cl}^{-}$, and water across cell membranes associated with glutamate receptor activation (Bourke and Tower, 1966; Rothman and Olney, 1986; Choi, 1987). To test the hypothesis that the acute neuronal swelling was an osmotically driven event, we added $100 \mathrm{~mm}$ sucrose (osmolarity increased approximately $1 / 3$ ) to the $\mathrm{BSS}_{0}$ exposure solution. Like $\mathrm{Na}^{+}$or $\mathrm{Cl}^{-}$substitution, addition of sucrose to $\mathrm{Ca}^{2+}$-containing $\mathrm{BSS}_{0}$ reduced acute neuronal swelling (not shown) but not delayed injury (Fig. 12). We considered the possibility that the surprising failure of extracellular $\mathrm{Ca}^{2+}$ removal to block oxygen-glucose deprivation-induced neuronal death was explained by the ability of the same maneuver to potentiate acute swelling. Indeed, when $100 \mathrm{~mm}$ sucrose was used to reduce acute swelling, neuronal death was then reduced by extracellular $\mathrm{Ca}^{2+}$ removal; increasing $\mathrm{Ca}^{2+}$ increased neuronal death (Fig. 12).

\section{${ }^{45} \mathrm{Ca}^{2+}$ accumulation}

Like rapidly triggered excitotoxicity (Kurth et al., 1989; Hartley et al., 1993), the neuronal injury induced by oxygen-glucose deprivation was associated with substantial movement of labeled extracellular $\mathrm{Ca}^{2+}$ into the cell layer (Marcoux et al., 1989). ${ }^{45} \mathrm{Ca}^{2+}$ uptake in cultures exposed to oxygen-glucose deprivation for 45-60 min was increased approximately four- to eightfold compared to sister cultures exposed only to normoxic wash conditions (Fig. 13A). No specific ${ }^{45} \mathrm{Ca}^{2+}$ uptake was observed in glial cultures following the same exposure conditions (Fig. $13 \mathrm{~A}$ ). Neuronal ${ }^{45} \mathrm{Ca}^{2+}$ accumulation was blocked by NMDA antagonists MK-801, dextrorphan, and D-APV, but not by 10 $\mu \mathrm{M}$ CNQX or $100 \mu \mathrm{M}$ nifedipine (Fig. 13B).

The amount of ${ }^{45} \mathrm{Ca}^{2+}$ accumulated during oxygen-glucose deprivation exposures correlated well with the extent of neuronal degeneration as assessed by $\mathrm{LDH}$ release the following day. The time course of ${ }^{45} \mathrm{Ca}^{2+}$ accumulation closely paralleled the development of subsequent neuronal injury (Fig. 13C); there was minimal specific uptake during exposures $<30 \mathrm{~min}$, and uptake increased progressively between 40 and $60 \mathrm{~min}$. When neuronal injury was reduced in a graded fashion by addition of 1-1000 $\mu_{\mathrm{M}}$ D-APV to the exposure solution, ${ }^{45} \mathrm{Ca}^{2+}$ uptake was reduced in parallel with neuronal loss (Fig. 13D).

\section{Discussion}

We have previously examined the injury of cultured cortical neurons induced by deprivation of either oxygen or glucose alone. The present study develops a quantitative characterization of the injury induced by deprivation of oxygen and glucose together. As in the single-deprivation paradigms, combined oxygen-glucose deprivation caused selective destruction of neurons but not glia. Combining the two insults greatly decreased the exposure time required to trigger widespread neuronal death-less than $1 \mathrm{hr}$ compared with more than $6 \mathrm{hr}$ for either oxygen or glucose deprivation alone under otherwise similar conditions. Because of this acceleration of injury induction, it was possible to examine several issues previously refractory to
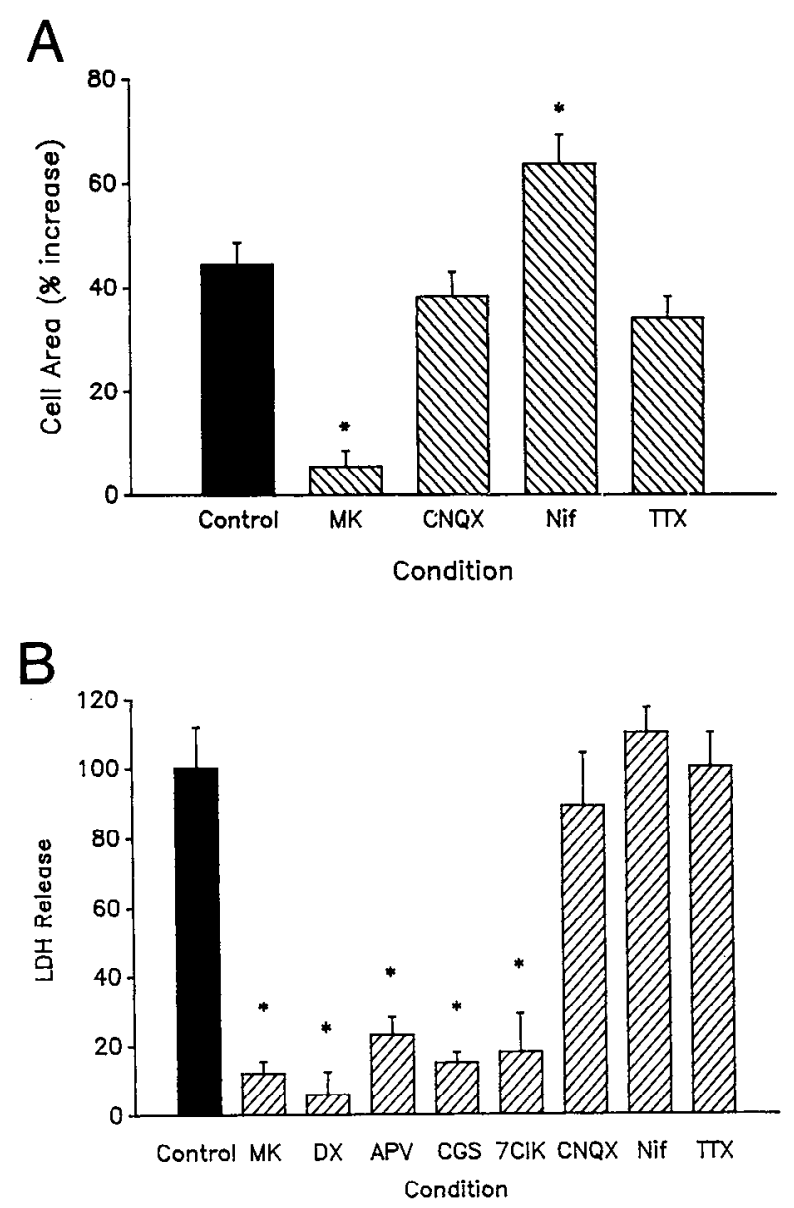

Figure 7. NMDA receptor antagonists reduce oxygen-glucose deprivation-induced injury. $A$, NMDA antagonists block acute neuronal swelling. Neuronal areas were measured from phase-contrast videomicrographs taken immediately after deprivation of oxygen and glucose for $50 \mathrm{~min}$, with no added drug (solid bar, control) or in the presence of the indicated antagonist (hatched bars): $M K, \mathrm{MK}-801,10 \mu \mathrm{M} ; C N Q X$, $10 \mu \mathrm{M} ;$ Nif, nifedipine, $100 \mu \mathrm{M}$; or TTX, tetrodotoxin, $10 \mu \mathrm{M}$. Values represent percentage change in neuronal area (mean $\pm \mathrm{SEM}, n=100$ neurons from three or four cultures in each condition), compared to neurons in sister cultures exposed only to normoxic wash conditions (actual area $=164 \pm 4.3 \mu \mathrm{m}^{2}$ ). $B$, NMDA antagonists block neuronal death. Cultures were deprived of oxygen and glucose for $45 \mathrm{~min}$, with no added drug (solid bar, control) or in the presence of the indicated antagonist (hatched bars): $M K$, MK-801, $30 \mu \mathrm{M} ; D X$, dextrorphan, 100 $\mu \mathrm{M} ; A P V$, D-aminophosphonovalerate, $1 \mathrm{~mm}$; $C G S$, CGS 19755, 100 $\mu \mathrm{M} ; 7 C l K, 7$-chlorokynurenate, $300 \mu \mathrm{M} ; C N Q X, 10 \mu \mathrm{M} ; N i f$, nifedipine, $100 \mu \mathrm{M}$; or $T T X, 10 \mu \mathrm{M}$. Drugs were present only during oxygen-glucose deprivation. Values represent mean LDH $\pm \operatorname{SEM}(n=3$ or 4$)$ i d after exposure, scaled to the mean LDH present in controls $(=100)$. Asterisks indicate significant difference $(p<0.05)$ from control by ANOVA and Student-Neuman-Keuls test.

study, including the existence of delayed injury, direct comparison of neuronal and glial vulnerability, effect of altering the extracellular ionic milieu, and correlation of extracellular ${ }^{45} \mathrm{Ca}^{2+}$ accumulation with subsequent neuronal death.

Figure 6. Blockade of oxygen-glucose deprivation-induced neuronal swelling and cell death by MK-801. Phase-contrast photomicrographs show identified fields of sister cultures before $(A)$, immediately after $(B)$, and $24 \mathrm{hr}$ after $(C) 50$ min oxygen-glucose deprivation. Left. control culture with no added drug; right, culture with $10 \mu \mathrm{M}$ MK-801 included in the exposure medium. Note prominent swelling of phase-bright neuronal cell bodies immediately following exposure. Scale bar, $50 \mu \mathrm{m}$. 

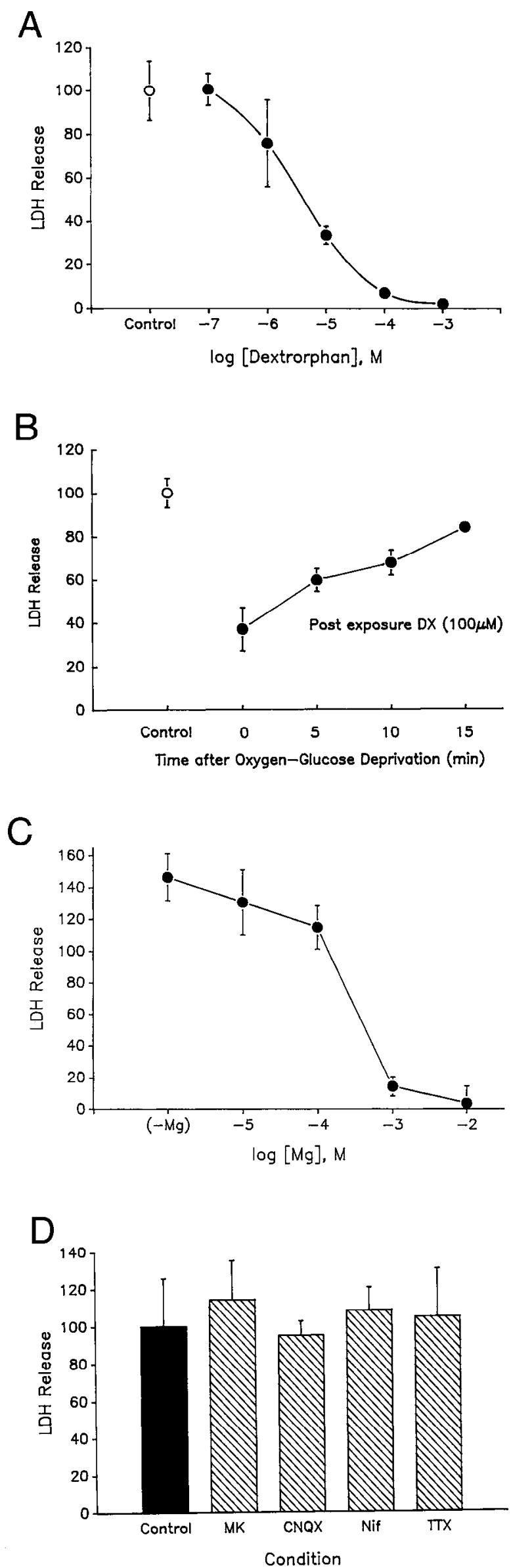

\section{Early and late components of hypoxic neuronal degeneration}

The gross morphologic changes of ischemic neuronal degeneration in vivo can appear hours to days after a vascular occlusive event (Pulsinelli et al., 1982a). In our previous studies of hypoxia or glucose deprivation in vitro, substantial neuronal damage was apparent even before the conclusion of the 6-8-hr-long insult. In contrast, the rapidity with which neuronal death was triggered by combined oxygen-glucose deprivation allowed delineation of a delayed component of neuronal degeneration, perhaps analogous to that seen in vivo. Immediately after oxygen-glucose deprivation, neurons in Nissl-stained, fixed cultures appeared generally unremarkable (Fig. 1); under phase contrast, neurons were swollen (Fig. 6) but had intact cell membranes and excluded trypan blue. Widespread neuronal degeneration occurred over the ensuing hours, despite the resupply of normal oxygen and glucose.

\section{Effect of glucose}

The observed destructive synergy between hypoxia and glucose deprivation was part of a more general inverse dependence of hypoxic neuronal degeneration on extracellular glucose concentration over the range of $0-20 \mathrm{~mm}$ (Fig. 2). With a starting glucose concentration of $20 \mathrm{~mm}$, even a $24 \mathrm{hr}$ period of hypoxia damaged less than half of the neuronal population.

Other in vitro studies have also suggested that an increased availability of extracellular glucose may reduce the impact of hypoxia on central neurons. In hippocampal slice, recovery from hypoxia-induced synaptic transmission failure depends directly on the concentration of extracellular glucose (Dong et al., 1988). Furthermore, hypoxic injury in striatal (Goldberg et al., 1986) or hippocampal cultures (Tombaugh and Sapolsky, 1990a) occurred only when both glucose and oxygen were removed from the exposure medium. Longer periods of combined oxygen and glucose deprivation $(5-6 \mathrm{hr}$ ) were needed to induce neuronal degeneration in those studies than in the present study; possible explanations include the differences in neuronal type, differences in experimental technique, or, in the striatal cultures, a lower density of glutamatergic synapses. It should be noted that $45-$ 60 min duration of oxygen-glucose deprivation required to produce irreversible neuronal loss in the present model is still longer than observed in models involving slice preparations or experimental stroke in vivo.

Elevated extracellular glucose might improve neuronal and

\footnotetext{
$\leftarrow$

Figure 8. Pharmacology of oxygen-glucose deprivation. $A$, Concentration-dependent injury reduction with the NMDA antagonist dextrorphan. Sister cultures were deprived of oxygen and glucose for 45 min with no added drug (open circle, control) or in the presence of dextrorphan at the indicated concentration (solid circles). Values represent mean $\mathrm{LDH} \pm \mathrm{SEM}(n=3$ or 4$)$, scaled to the mean LDH present in controls $(=100)$. $B$, Partial protection with postexposure NMDA antagonist. Cultures were deprived of oxygen and glucose for $40 \mathrm{~min}$ in normal $\mathrm{BSS}_{0}$, and dextrorphan was added at the indicated time following exposure. $C$, Removal of extracellular $\mathbf{M g}^{2+}$ enhances oxygenglucose deprivation injury. Cultures were deprived of oxygen and glucose for $40 \mathrm{~min}$ (producing in this experiment minimal injury in normal $\mathrm{Mg}^{2+}$ ) in the presence of the indicated added $\mathrm{Mg}^{2+}$ concentration. Values represent mean LDH $\pm \operatorname{SEM}(n=3$ or 4$)$, scaled to the mean LDH present in cultures with no added $\mathrm{Mg}^{2+} . D$, No tested drug blocks glial injury following oxygen-glucose deprivation. Glial cultures were deprived of oxygen and glucose for $6 \mathrm{hr}$, with no added drug (solid bar, control) or in the presence of the indicated antagonist (hatched bars): $M K, \mathrm{MK}-801,30 \mu \mathrm{M} ; C N Q X, 100 \mu \mathrm{M} ; N i f$, nifedipine, $100 \mu \mathrm{M}$; or TTX, tetrodotoxin, $10 \mu \mathrm{M}$.
} 

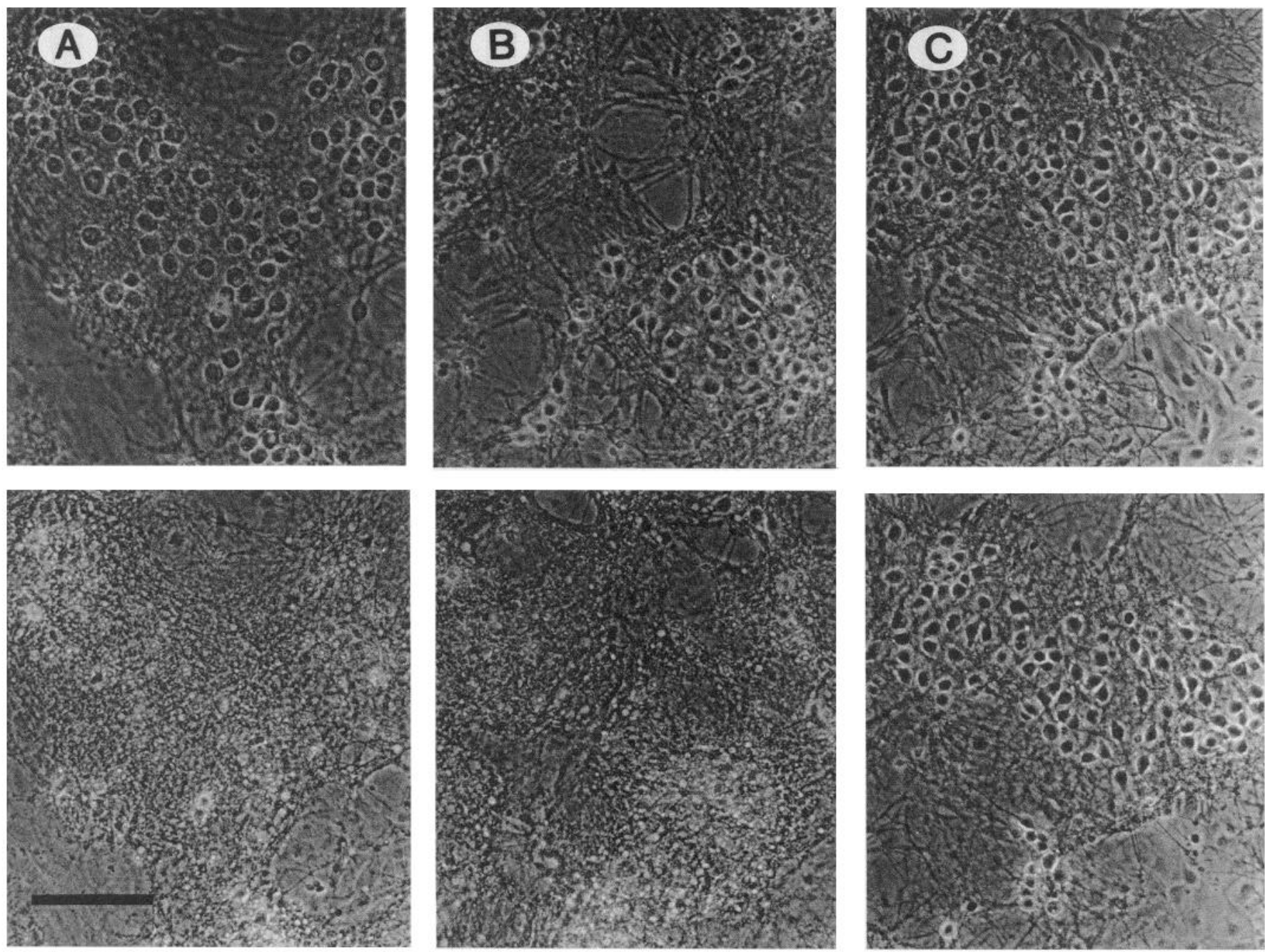

Figure 9. Effect of calcium and sodium removal on oxygen-glucose deprivation-induced neuronal injury. Phase-contrast photomicrographs demonstrate neuronal morphology in representative fields immediately after $45 \mathrm{~min}$ oxygen-glucose deprivation (top panels) and in the same microscopic fields $1 \mathrm{~d}$ later (bottom panels). In this figure, exposure was terminated by replacing experimental medium with MEM containing oxygen and $5.5 \mathrm{~mm}$ glucose and returning cultures to the normoxic incubator. $A$, Exposure in $\mathrm{BSS}_{0}$ with no added $\mathrm{Ca}^{2+}$. Note marked acute neuronal swelling followed by widespread neuronal death. $B$, Exposure in $\mathrm{BSS}_{0}$ with $\mathrm{NaCl}$ replaced with choline chloride, resulting in early preservation of neuronal morphology but not reduction in delayed neuronal loss. $C$, Exposure in $\mathrm{BSS}_{0}$ with low $\mathrm{Na}^{+}$and no added $\mathrm{Ca}^{2+}$, blocking both early and late manifestations of neuronal injury. Scale bar, $100 \mu \mathrm{m}$.

glial cell energy status, leading to reduced glutamate efflux, increased glutamate uptake, or improved $\mathrm{Ca}^{2+}$ homeostasis. Improving the glycogen content of astrocytes in our cortical cultures reduces vulnerability to damage by glucose deprivation (Swanson and Choi, 1993). In contrast, in some in vivo models elevated preischemic blood glucose levels worsen cerebral infarction (Welsh et al., 1980; Pulsinelli et al., 1982b). The key difference may be that lactic acid accumulates to a greater extent in vivo than in vitro; deleterious effects of lactic acidosis (Plum, 1983) outweigh the benefits of increased glucose availability on neuronal survival. In the immature brain, high glucose levels are not detrimental, perhaps due to decreased intracerebral lactate accumulation (Voorhies et al., 1986; Hattori and Wasterlain, 1990).

\section{Glial vulnerability}

Consistent with in vivo observations, cultured astrocytes were much more resistant than neurons to damage by oxygen-glucose deprivation. Half-maximal destruction of cultured astrocytes required approximately a $6 \mathrm{hr}$ exposure (Fig. 4), roughly eightfold longer than the $45 \mathrm{~min}$ required for half-maximal neuronal injury under the same experimental conditions (Fig. 2). Similarly, isolated glucose deprivation resulted in half-maximal glial injury after approximately $36 \mathrm{hr}$, compared to $6-8 \mathrm{hr}$ for neurons. If extracellular glucose was continuously maintained around $5 \mathrm{~mm}$, glia were profoundly resistant to oxygen deprivation, surviving as long as $5 \mathrm{~d}$. This powerful protective effect of glucose on hypoxic glial injury is consistent with other in vitro observations (Yu et al., 1989; Callahan et al., 1990; Haun et al., 1991) and suggests that cultured glia, unlike neurons, may be able to survive for extended periods using glycolytic metabolism alone. The resistance of astrocytes to oxygen-glucose deprivation may be viewed as a target for neuroprotective strategies: if all of the mechanisms responsible for heightened neuronal vulnerability can be counteracted, perhaps neuronal vulnerability can be made to resemble glial vulnerability. 

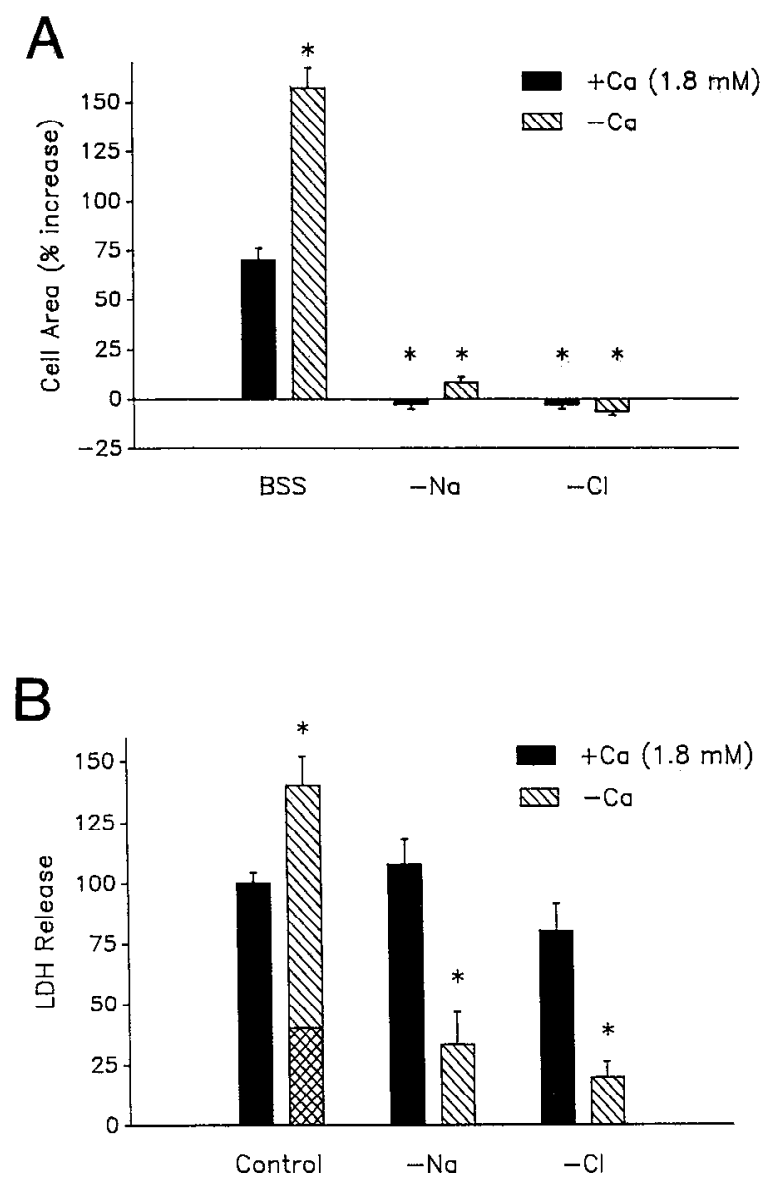

Figure 10. Ionic dependence of cell swelling and of delayed death following oxygen-glucose deprivation. $A$, Cell areas of individual neurons measured from phase-contrast videomicrographs immediately after $45 \mathrm{~min}$ oxygen-glucose deprivation. Values represent percentage increase in neuronal area (mean \pm SEM, 42-100 consecutively measured neurons from three or four cultures each) compared to mean area of neurons in sister cultures exposed to normoxic wash conditions (actual mean area $\left.=188 \pm 3.1 \mu \mathrm{m}^{2}\right)$. Substantial swelling was sccn during oxygen-glucose deprivation in normal $\mathrm{BSS}_{0}$ (solid bar); this was increased by exposure in $\mathrm{BSS}_{0}$ without added $\mathrm{Ca}^{2+}$ and was blocked by $\mathrm{Na}^{+}$or $\mathrm{Cl}^{-}$substitution. $B$, Neuronal loss $1 \mathrm{~d}$ after 45 min oxygenglucose deprivation. Bars represent mean LDH \pm SEM $(n=3$ or 4$)$, scaled to mean $\mathrm{LDH}$ measured in cultures exposed in $\mathrm{BSS}_{0}$ with normal ionic composition ( $=100$, solid bar). Cross-hatched area indicates LDH present in exposure medium before medium replacement. Asterisks indicate significant difference $(p<0.05)$ from $\mathrm{BSS}_{0}$ control by ANOVA and Student-Neuman-Keuls test.

\section{Pharmacology of oxygen-glucose deprivation injury}

Inclusion of selective NMDA antagonists during the exposure period blocked both acute neuronal swelling and late neuronal degeneration with associated efflux of LDH to the bathing medium. This was not confined to a specific mechanism of receptor blockade, as it was observed using competitive antagonists of the glutamate recognition site of the NMDA receptor (D-APV, CGS 19755), a competitive blocker of the strychnine-insensitive glycine site (7-chlorokynurenate), as well as noncompetitive NMDA antagonists including MK-801 and dextrorphan (Fig. 7). In addition, removal of extracellular $\mathrm{Mg}^{2+}$, which would be expected to enhance NMDA channel activation (Mayer et al., 1984; Nowak et al., 1984) and increase glutamate-mediated toxicity (Finkbeiner and Stevens, 1988), substantially increased injury (Fig. 8C). With briefer insult durations ( $<50-60 \mathrm{~min}$ ),

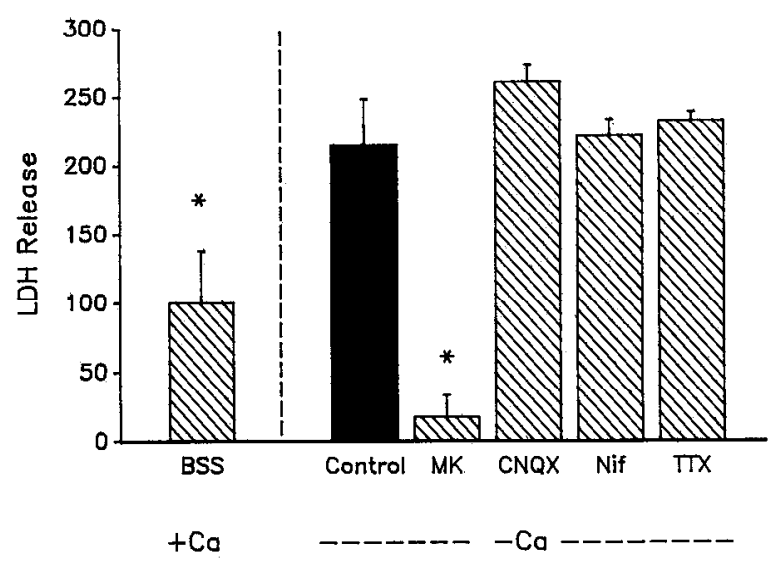

Figure 11. Pharmacology of oxygen-glucose deprivation neuronal injury in $-\mathrm{Ca}^{2+}$ medium. Cultures were deprived of oxygen and glucose, in normal $\mathrm{BSS}_{0}$ or in $\mathrm{BSS}_{0}$ with no added $\mathrm{Ca}^{2+}$, in the presence of the indicated antagonist. Antagonist abbreviations and concentrations are as in Figure $7 A$. Significantly different $(p<0.05)$ from $-\mathrm{Ca}^{2+}$ control $\left.{ }^{*}\right)$ by ANOVA and Student-Newman-Keuls test.

partial neuroprotective effects were seen even when NMDA antagonists were not added until after insult conclusion and return to normal oxygen and glucose (Fig. $8 B$ ).

These results indicate that the injury induced by combined oxygen-glucose deprivation, like the injury induced in vitro by glutamate exposure (Choi, 1987), hypoxia (Goldberg et al., 1987), or glucose deprivation (Monyer et al., 1989), or like the injury induced in vivo by focal hypoxia-ischemia (see Albers et al., 1989), is substantially mediated by NMDA receptors. It is noteworthy that high concentrations of the competitive NMDA antagonist D-APV were required (Fig. $13 D ; \mathrm{EC}_{50}, 100-300 \mu \mathrm{M}$ ), compared to about $10 \mu \mathrm{M}$ against a pure hypoxic insult (Goldberg et al., 1987), suggesting that effective extracellular glutamate concentrations may reach higher levels after oxygen-glucose deprivation than after oxygen or glucose deprivation alone. This requirement for high concentrations of competitive antagonists may account for the incomplete neuroprotective effects of glutamate receptor blockade described in previous studies of oxygen-glucose deprivation in cultured striatal (Goldberg et al., 1986) and hippocampal (Tombaugh and Sapolsky, 1990a) neurons.

NMDA antagonists blocked oxygen-glucose deprivation-induced acute neuronal swelling as well as cell death (Fig. 6). The degree of swelling reduction was somewhat unexpected, as neuronal swelling induced by brief glutamate exposure is only partially attenuated by NMDA antagonists (Choi et al., 1987). One possible explanation is that NMDA receptor activation may play a more critical role than non-NMDA receptors in hypoxic cortical injury, compared to injury induced by exogenously applied glutamate. Alternatively, the neuroprotective actions of NMDA antagonists may be mediated by reduction of presynaptic glutamate release as well as postsynaptic glutamate neurotoxicity (Bustos et al., 1992; Choi and Lobner, 1993).

In contrast to the neuroprotection afforded by NMDA receptor blockade, the AMPA/kainate receptor antagonist CNQX was ineffective at selective concentrations $(<30 \mu \mathrm{M})$. This observation is consistent with the inability of CNQX to block the rapidly triggered excitotoxic injury induced by brief, intense glutamate exposure (Koh and Choi, 1991). It does not exclude a contribution of AMPA or kainate receptors to injury. On cortical neurons, AMPA or kainate receptors mediate a more 


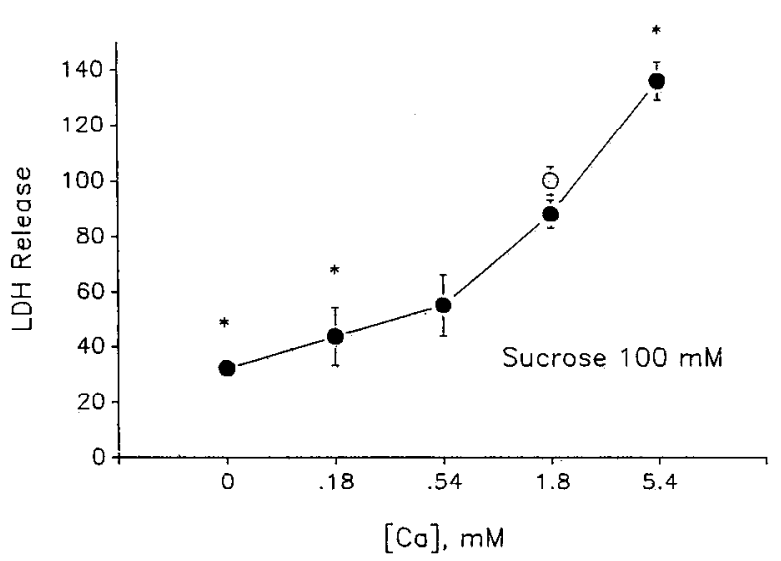

Figure 12. Calcium dependence of oxygen-glucose deprivation injury under hyperosmolar conditions. Sister cultures were deprived of oxygen and glucose for $45 \mathrm{~min}$ in the presence of the indicated $\mathrm{Ca}^{2+}$ concentration, in normal $\mathrm{BSS}_{0}$ (open circle) or with addition of $100 \mathrm{~mm}$ sucrose (solid circles). Values represent mean LDH $\pm \operatorname{SEM}(n=4)$, scaled to LDH from cultures exposed in $\mathrm{BSS}_{0}$ with normal $\mathrm{Ca}^{2+}$ and no added sucrose $(=100$, open circle $)$. Asterisks indicate significant difference $(p$ $<0.05$ ) from control by ANOVA and Student-Neuman-Keuls test.

slowly triggered excitotoxic injury than NMDA receptors (Frandsen et al., 1989; Choi, 1990a; Koh et al., 1990); thus, NMDA receptor overstimulation may reach lethal levels first, masking injury mediated by AMPA or kainate receptors. If NMDA receptor-mediated injury is blocked by saturating levels of an NMDA antagonist, then addition of low concentrations of CNQX produce substantial neuroprotection against a prolonged oxygen-glucose deprivation insult (Kaku et al., 1991). The promising protective effects of AMPA/kainate antagonists recently observed in animal models of global ischemia (Sheardown et al., 1990; Buchan et al., 1991) may occur because NMDA receptor-mediated injury has been attenuated by endogenous factors (Choi, 1990b), such as extracellular acidity (Giffard et al., 1990a; Tang et al., 1990; Tombaugh and Sapolsky, 1990b) or zinc concentration (Koh and Choi, 1988).

The pharmacological similarity between rapidly triggered, NMDA receptor-mediated excitotoxic injury, and oxygen-glucose deprivation-induced injury extended to dihydropyridine antagonists of voltage-gated calcium channels. High concentra-

Figure 13. $A$, Selective neuronal accumulation of ${ }^{45} \mathrm{Ca}^{2+}$ during oxygen-glucose deprivation. Cultures were exposed to normoxic wash conditions or to oxygen-glucose deprivation for $60 \mathrm{~min}$ in the presence of trace ${ }^{45} \mathrm{Ca}^{2+}$, and total intracellular accumulation was measured after thorough washing. Left, mixed cultures (neurons + glia); right, glial cultures. $B,{ }^{45} \mathrm{Ca}^{2+}$ accumulation is blocked by NMDA antagonists. Bars represent mean neuronal ${ }^{45} \mathrm{Ca}^{2+}$ accumulation after $45 \mathrm{~min}$ oxygenglucose deprivation in the presence of the indicated antagonist, scaled to ${ }^{45} \mathrm{Ca}^{2+}$ present in controls $(=100$, solid bar). Antagonist concentrations: $M K$, MK $-801,100 \mu \mathrm{M} ; D X$, dextrorphan, $100 \mu \mathrm{M} ; C G S$, CGS 19755, $100 \mu \mathrm{M} ; 7 C I K$, 7-chlorokynurenate, $300 \mu \mathrm{M} ; C N Q X, 100 \mu \mathrm{M}$, Nif, nifedipine, $100 \mu \mathrm{M} ; \mathrm{Nim}$, nimodipine, $30 \mu \mathrm{M}$. Asterisks indicate significant difference $(p<0.05)$ from control by ANOVA and StudentNeuman-Keuls test. $C$, Time course of oxygen-glucose deprivation. Values represent mean ${ }^{45} \mathrm{Ca}^{2+}$ accumulation during oxygen-glucose deprivation for the indicated duration (open circles) or $\mathrm{LDH}$ release the next day (solid circles), both scaled to mean values measured after 60 min oxygen-glucose deprivation. $D$, Concentration dependence of blockade by D-APV. Cultures were deprived of oxygen and glucose for 45 min with no added drug (control), or with addition of the indicated concentration of D-APV. Values are as indicated in $C$.
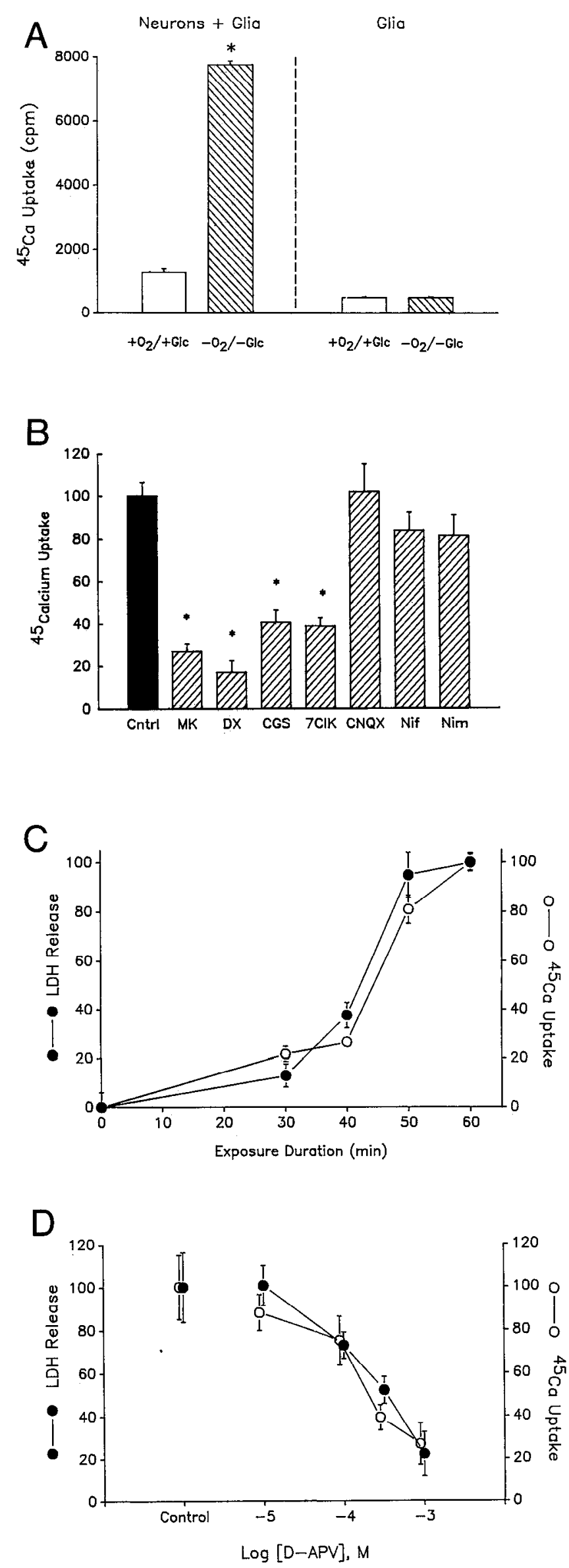
tions of these drugs, ineffective against rapidly triggered excitotoxic injury in our system, were also ineffective against the neuronal injury induced by oxygen-glucose deprivation. Marcoux et al. (1989) also found that several voltage-gated calcium channel antagonists did not protect rat brain cultures against an oxygen-glucose deprivation insult. In vivo, dihydropyridines have been shown to reduce ischemic intracellular $\mathrm{Ca}^{2+}$ accumulation (Uematsu et al., 1989), although neuroprotective effects have been mixed (Hossmann, 1990); protective effects may be more clear-cut if the drugs are combined with an NMDA antagonist (Uematsu et al., 1989).

\section{Glutamate efflux}

Pharmacological blockade of oxygen-glucose deprivation injury by NMDA antagonists supports the hypothesis that neuronal injury in this model results from toxic activation of glutamate receptors, presumably reflecting excessive amounts of endogenous glutamate in the vicinity of neuronal glutamate receptors (Benveniste et al., 1984; Drejer et al., 1985). We found that extracellular medium glutamate increased substantially during oxygen-glucose deprivation and that this increase first occurred after a duration of insult sufficient to induce neuronal death. However, the concentrations measured in the bathing medium never exceeded the low micromolar range, far less than that needed to kill cortical neurons in healthy mixed cultures (Choi et al., 1987).

Several explanations may be put forward to explain this apparent discrepancy. First and most important, the concentration of glutamate in the bathing medium may not accurately reflect levels local to postsynaptic glutamate receptors. Indeed, the high concentrations of the competitive antagonist $D$-APV required for protective efficacy suggest that glutamate levels at effective cellular sites are much higher than medium concentrations indicate. Second, the glutamate concentrations required to kill energy-depleted neurons (Novelli et al., 1988) or neurons near energy-depleted glia (Kauppinen et al., 1988; Rosenberg and Aizenman, 1989) might be considerably less than those required to kill neurons in normal mixed cell cultures. Finally, it remains possible that compounds other than glutamate or aspartate might contribute to the toxic activation of NMDA receptors.

\section{Role of $\mathrm{Ca}^{2+}$ in oxygen-glucose deprivation neuronal injury}

We originally predicted that the removal of extracellular $\mathrm{Ca}^{2+}$ would ameliorate oxygen-glucose deprivation neuronal death. However, this manipulation actually increased the death induced by submaximal insults (Figs. 9, 10). This paradoxical enhancement is probably explained by the observed potentiation of acute neuronal swelling, leading to frank cell lysis and $\mathrm{LDH}$ release. Removal of extracellular $\mathrm{Ca}^{2+}$ also potentiated neuronal swelling after $5 \mathrm{~min}$ exposure to exogenous glutamate (Choi, 1987), but cell death was decreased, perhaps because cultures were returned to normal ionic solutions before cell lysis occurred. If glutamate or NMDA exposures are extended to 50 min, then $\mathrm{Ca}^{2+}$ removal does increase both early neuronal swelling and cell death (M. P. Goldberg and D. W. Choi, unpublished observations).

The marked neuronal swelling induced by oxygen-glucose deprivation in the absence of extracellular $\mathrm{Ca}^{2+}$ was specifically dependent on NMDA receptor activation, since it could be blocked by NMDA antagonists but not by CNQX, TTX, or nifedipine. The swelling also depended on extracellular $\mathrm{Na}^{+}$and
$\mathrm{Cl}^{-} . \mathrm{Ca}^{2+}$ removal may enhance $\mathrm{Na}^{+}$influx through the NMDA receptor-gated channels by reducing ionic interference or $\mathrm{Ca}^{2+}$ dependent desensitization; enhanced $\mathrm{Na}^{+}$influx together with passive transfer of $\mathrm{Cl}^{-}$and water presumably leads to the observed expansion of intracellular volume. $\mathrm{Ca}^{2+}$ removal may also promote swelling by other means, including reduction of membrane mechanical stability, enhancement of neuronal burst firing (Konnerth et al., 1986), and enhancement of ATP depletion (Lobner and Lipton, 1991).

If neuronal swelling was limited by replacement of extracellular $\mathrm{Na}^{+}$or $\mathrm{Cl}^{-}$, or by sucrose addition to raise extracellular osmolarity, late neuronal degeneration still occurred. However, if $\mathrm{Ca}^{2+}$ was then removed from the bathing medium, late neuronal degeneration was attenuated (Figs. 9-11). Although $\mathrm{Na}^{+}$ replacement during the exposure period was not itself protective, we cannot exclude a synergistic toxicity of $\mathrm{Na}^{+}$together with $\mathrm{Ca}^{2+}$. Kiedrowski et al. (1992) have recently observed sustained elevation of intracellular $\left[\mathrm{Na}^{+}\right]$as well as $\left[\mathrm{Ca}^{2+}\right]$ following toxic glutamate exposure.

Supporting the importance of the $\mathrm{Ca}^{2+}$-dependent injury component was the observed close relationship between the uptake of ${ }^{45} \mathrm{Ca}^{2+}$ induced by oxygen-glucose deprivation and subsequent cell death (Fig. 13C,D). Marcoux et al. (1990) have observed increased ${ }^{45} \mathrm{Ca}^{2+}$ accumulation in cortical cultures $12 \mathrm{hr}$ following isolated hypoxia. In the present, more rapid injury paradigm, substantial $\mathrm{Ca}^{2+}$ entry occurred during the period of oxygen-glucose deprivation itself. For the exposure durations studied (up to $60 \mathrm{~min}$ ), such uptake was largely neuronal, as glial cultures showed no enhanced ${ }^{45} \mathrm{Ca}^{2+}$ uptake under matched conditions (Fig. 13A).

The exact relationship between transmembrane $\mathrm{Ca}^{2+}$ influx and cytosolic free $\mathrm{Ca}^{2+}$ concentration $\left(\left[\mathrm{Ca}^{2+}\right]_{i}\right.$ ) remains to be established. In cortical culture, neuronal $\left[\mathrm{Ca}^{2+}\right]_{i}$ increases up to 10 -fold over basal levels during oxygen-glucose deprivation (Goldberg and Choi, 1990). However, large cyanide-induced elevations in $\left[\mathrm{Ca}^{2+}\right]_{i}$ in hippocampal neurons can occur dissociated from cell death (Dubinsky and Rothman, 1991), suggesting that the mechanism of $\left[\mathrm{Ca}^{2+}\right]_{i}$ elevation may be important. As $\left[\mathrm{Ca}^{2+}\right]_{i}$ represents only a small fraction of total cell $\mathrm{Ca}^{2+}$, it is possible that $\mathrm{Ca}^{2+}$ entry measured by ${ }^{45} \mathrm{Ca}^{2+}$ accumulation may more accurately reflect the cell damage induced during energy depletion than measurements of cell body $\left[\mathrm{Ca}^{2+}\right]_{i}$.

These results suggest that two injury components can be delineated; the first independent of extracellular $\mathrm{Ca}^{2+}$, and a second dependent on extracellular $\mathrm{Ca}^{2+}$. Acute neuronal swelling is enhanced when $\mathrm{Ca}^{2+}$ is removed from the bathing medium; it depends on extracellular $\mathrm{Na}^{+}$and $\mathrm{Cl}^{-1}$ and can be attenuated by adding extracellular sucrose. The second injury component, delayed cell degeneration, is mediated primarily by $\mathrm{Ca}^{2+}$ entry. The importance of $\mathrm{Ca}^{2+}$-independent acute cell swelling may be exaggerated in the open architecture of dissociated cell culture. In vivo, the small volume of extracellular space and fixed cranial size limit changes in ischemic cell size. Our observations suggest that both forms of injury involve excessive release of glutamate and toxic overactivation of NMDA receptors.

\section{References}

Albers GW, Goldberg MP, Choi DW (1989) $N$-methyl-D-aspartate antagonists: ready for clinical trial in brain ischemia? Ann Neurol 25: 398-403.

Ames A, Nesbett FB (1983) Pathophysiology of ischemic cell death: III. Role of extracellular factors. Stroke 14:233-240. 
Benveniste H, Drejer I, Schousboe A, Diemer NH (1984) Elevation of the extracellular concentrations of glutamate and aspartate in rat hippocampus during transient cerebral ischemia monitored by intracerebral microdialysis. J Neurochem 43:1369-1374.

Bourke RS, Tower DB (1966) Fluid compartmentation and electrolytes of cat cerebral cortex in vitro. I. Swelling and solute distribution in mature cerebral cortex. J Neurochem 13:1071-1097.

Buchan AM, Li H, Cho S, Pulsinelli WA (1991) Blockade of the AMPA receptor prevents CA1 hippocampal injury following severe but transient ischemia in adult rats. Neurosci Lett 132:255-258.

Bustos G, Abarca J, Forray MI, Gysling K, Bradberry CW, Roth RH (1992) Regulation of excitatory amino acid release by $N$-methylD-aspartate receptors in rat striatum: in vivo microdialysis studies. Brain Res 585:105-115.

Callahan DJ, Engle MJ, Volpe JJ (1990) Hypoxic injury to developing glial cells: protective effect of high glucose. Pediatr Res 27:186-190.

Choi DW (1987) Ionic dependence of glutamate neurotoxicity in cortical cell culture. J Neurosci 7:369-379.

Choi DW (1988) Glutamate neurotoxicity and diseases of the nervous system. Neuron 1:623-634.

Choi DW (1990a) Cerebral hypoxia-some new approaches and unanswered questions. J Neurosci 10:2493-2501.

Choi DW (1990b) Possible mechanisms limiting $N$-methyl-D-aspartate receptor overactivation and the therapeutic efficacy of $N$-methylD-aspartate antagonists. Stroke 21:III20-III22.

Choi DW, Lobner DC (1993) MK-801 attenuates glutamate release induced by oxygen/glucose deprivation in cultured cortical neurons. Neurology, in press.

Choi DW, Maulucci Gedde MA, Kriegstein AR (1987) Glutamate neurotoxicity in cortical cell culture. J Neurosci 7:357-368.

Dong WQ, Schurr A, Reid KH, Shields CB, West CA (1988) The rat hippocampal slice preparation as an in vitro model of ischemia. Stroke 19:498-502.

Drejer J, Benveniste H, Diemer NH, Schousboe A (1985) Cellular origir of ischemia-induced glutamate release from brain tissue in vivo and in vitro. $\mathbf{J}$ Neurochem 45:145-151.

Dubinsky JM, Rothman SM (1991) Intracellular calcium concentrations during "chemical hypoxia" and excitotoxic neuronal injury. $\mathbf{J}$ Neurosci 11:2545-2551.

Finkbeiner S, Stevens CF (1988) Applications of quantitative measurements for assessing glutamate neurotoxicity. Proc Natl Acad Sci USA 85:4071-4074.

Frandsen A, Drejer J, Schousboe A (1989) Direct evidence that excitotoxicity in cultured neurons is mediated via $N$-methyl-D-aspartate (NMDA) as well as non-NMDA receptors. J Neurochem 53:297-299.

Giffard RG, Monyer H, Christine CW, Choi DW (1990a) Acidosis reduces NMDA receptor activation, glutamate neurotoxicity, and oxygen-glucose deprivation neuronal injury in cortical cultures. Brain Res 506:339-342.

Giffard RG, Monyer H, Choi DW (1990b) Selective vulnerability of cultured cortical glia to injury by extracellular acidosis. Brain Res 530:138-141.

Goldberg MP, Choi DW (1990) Intracellular free calcium increases in cultured cortical neurons deprived of oxygen and glucose. Stroke 21:III75-III77.

Goldberg MP, Weiss JW, Pham PC, Choi DW (1987) $N$-methyl$D$-aspartate receptors mediate hypoxic neuronal injury in cortical culture. J Pharmacol Exp Ther 243:784-791.

Goldberg MP, Monyer H, Choi DW (1988a) Cortical neuronal injury in vitro following combined glucose and oxygen deprivation: ionic dependence and delayed protection by NMDA antagonists. Soc Neurosci Abstr 14:745.

Goldberg MP, Monyer H, Choi DW (1988b) Hypoxic neuronal injury in vitro depends on extracellular glutamine. Neurosci Lett 94:52-57.

Goldberg MP, Kurth MC, Giffard RG, Choi DW (1989) 45-Calcium accumulation and intracellular calcium during in vitro "ischemia." Soc Neurosci Abstr 15:803.

Goldbcrg WJ, Kadingo RM, Barrett JN (1986) Effects of ischcmialike conditions on cultured neurons: protection by low $\mathrm{Na}^{+}$, low $\mathrm{Ca}^{2+}$ solutions. J Neurosci 6:3144-3151.

Hartley DM, Kurth MC, Bjerkness L, Weiss JH, Choi DW (1993) Glutamate receptor-induced ${ }^{45} \mathrm{Ca}^{2+}$ accumulation in cortical cell culture correlates with subsequent neuronal degeneration. J Neurosci 13:1993-2000.

Hattori H, Wasterlain CG (1990) Posthypoxic glucose supplement reduces hypoxic-ischemic brain damage in the neonatal rat. Ann Neurol 28:122-128.

Haun SE, Murphy EJ, Bates CM, Horrocks LA (1991) Astrocytic cell death secondary to combined glucose-oxygen deprivation is dependent on extracellular calcium. Soc Neurosci Abstr 17:184.

Hossmann KA (1990) Calcium antagonists for the treatment of brain ischemia: a critical appraisal. In: Pharmacology of cerebral ischemia 1990 (Krieglstein J, Oberpichler H, eds), pp 53-63. Stuttgart: Wissenschaftliche.

Kaku DA, Goldberg MP, Choi DW (1991) Antagonism of non-NMDA receptors aguments the neuroprotective effect of NMDA receptor blockade in cortical cultures subjected to prolonged deprivation of oxygen and glucose. Brain Res 554:344-347.

Kauppinen RA, Enkvist K, Holopainen I, Akerman KE (1988) Glùcose deprivation depolarizes plasma membrane of cultured astrocytes and collapses transmembrane potassium and glutamate gradients. Neuroscience 26:283-289.

Kiedrowski L, Brooker G, Costa E, Wroblewski JT (1992) Contribution of $\mathrm{Na} / \mathrm{Ca}$ exchange and $\mathrm{Na} / \mathrm{K}$ ATPase in $\mathrm{Ca}^{2+}$ homeostasis: role in ganglioside protection against glutamate neurotoxicity. Soc Neurosci Abstr 18:1147.

Koh J, Choi DW (1987) Quantitative determination of glutamate mediated cortical neuronal injury in cell culture by lactate dehydrogenase efflux assay. J Neurosci Methods 20:83-90.

Koh J, Choi DW (1988) Zinc alters excitatory amino acid neurotoxicity on cortical neurons. J Neurosci 8:2164-2171.

Koh J, Choi DW (1991) Selective blockade of non-NMDA receptors does not block rapidly triggered glutamate-induced neuronal death. Brain Res 548:318-321.

Koh J, Goldberg MP, Hartley DM, Choi DW (1990) Non-NMDA receptor-mediated neurotoxicity in cortical culture. J Neurosci 10: 693-705.

Konnerth A, Heinemann U, Yaari Y (1986) Nonsynaptic epileptogenesis in the mammalian hippocampus in vitro. I. Development of seizurelike activity in low extracellular calcium. J Neurophysiol 56: 409-423.

Kurth MC, Weiss JH, Choi DW (1989) Relationship between glutamate-induced ${ }^{45} \mathrm{Ca}$ influx and resultant neuronal injury in cultured cortical neurons. Neurology 39:217.

Lindroth P, Mopper K (1979) High performance liquid chromatographic determination of subpicomole amounts of amino acids by precolumn fluorescence derivatization with $o$-phthaldialdehyde. Anal Chem 51:1667-1674.

Lobner D, Lipton P (1991) Effects of low calcium and NMDA antagonist on ATP during "ischemia" in the rat hippocampal slice. Soc Neurosci Abstr 17:184.

MacDermott AB, Mayer ML, Westbrook GL, Smith SJ, Barker JL (1986) NMDA-receptor activation increases cytoplasmic calcium concentration in cultured spinal cord neurones. Nature 321:519-522.

Marcoux FW, Probert AW Jr, Weber ML (1989) Hypoxic injury in cell culture: calcium accumulation blockade and neuroprotection by NMDA antagonists but not calcium-channel antagonists. In: Cerebrovascular diseaes (Ginsberg MD, Dietrich WD, eds), pp 135-141. New York: Raven.

Marcoux FW, Probert AJ, Weber ML (1990) Hypoxic neuronal injury in tissue culture is associated with delayed calcium accumulation. Stroke 21:III71-III74.

Mayer ML, Westbrook GL, Guthrie PB (1984) Voltage-dependent block by $\mathrm{Mg}^{2+}$ of NMDA responses in spinal cord neurones. Nature 309:261-263.

McCarthy KD, de Vellis J (1980) Preparation of separate astroglial and oligodendroglial cell cultures from rat cerebral tissue. J Cell Biol 85:890-902.

Meldrum B (1985) Possible therapeutic applications of antagonists of excitatory amino acid neurotransmitters. Clin Sci 68:113-122.

Monyer H, Choi DW (1990) Glucose deprivation neuronal injury in vitro is modified by withdrawal of extracellular glutamine. $\mathbf{J}$ Cereb Blood Flow Metab 10:337-342.

Monyer H, Goldberg MP, Choi DW (1989) Glucose deprivation neuronal injury in cortical culture. Brain Res 483:347-354.

Nedergaard M (1991) Energy depletion kills neurons independently of cytosolic calcium. J Cereb Blood Flow Metab 11[Suppl 2]:S421.

Novelli A, Reilly JA, Lysko PG, Henneberry RC (1988) Glutamate becomes neurotoxic via the $N$-methyl-D-aspartate receptor when intracellular energy levels are reduced. Brain Res 451:205-212. 
Nowak L, Bregestovski P, Ascher P, Herbet A, Prochiantz A (1984) Magnesium gates glutamate-activated channels in mouse central neurones. Nature 307:462-465.

Olsen RW, Szamraj O, Houser CR (1987) [3H]AMPA binding to glutamate receptor subpopulations in rat brain. Brain Res 402:243254.

Plum F (1983) What causes infarction in ischemic brain? The Robert Wartenberg Lecture. Neurology 33:222-233.

Pulsinelli WA, Brierly JB, Plum F (1982a) Temporal profile of neuronal damage in a model of transient forebrain ischemia. Ann Neurol $11: 491-498$.

Pulsinelli WA, Waldman S, Rawlinson D, Plum F (1982b) Moderate hyperglycemia augments ischemic brain damage: a neuropathologic study in the rat. Neurology 32:1239-1246.

Raley-Susman KM, Lipton P (1990) In vitro ischemia and protein synthesis in the rat hippocampal slice: the role of calcium and NMDA receptor activation. Brain Res 515:27-38.

Rose K, Goldberg MP, Choi DW (1993) Cytotoxicity in murine cortical cell culture. In: In vitro biological methods. Methods in toxicology (Tyson CA, Frazier JM, eds), pp 46-60. San Diego: Academic.

Rosenberg PA, Aizenman E (1989) Hundred-fold increase in neuronal vulnerability to glutamate toxicity in astrocyte-poor cultures of rat cerebral cortex. Neurosci Lett 103:162-168.

Rothman SM, Olney JW (1986) Glutamate and the pathophysiology of hypoxic-ischemic brain damage. Ann Neurol 19:105-111.

Sheardown MJ, Nielsen EO, Hansen AJ, Jacobsen P, Honore T (1990) 2,3-Dihydroxy-6-nitro-7-sulfamoyl-benzo(F)quinoxaline: a neuroprotectant for cerebral ischemia. Science 247:571-574.

Siesjo BK, Bengtsson F (1989) Calcium fluxes, calcium antagonists, and calcium-related pathology in brain ischemia, hypoglycemia, and spreading depression: a unifying hypothesis. J Cereb Blood Flow Metab 9:127-140.

Swanson RA, Choi DW (1993) Glial glycogen stores affect neuronal survival during glucose deprivation in vitro. $\mathrm{J}$ Cereb Blood Flow Metab 13:162-169.

Tang C-M, Dichter M, Morad M (1990) Modulation of the $N$-methylD-aspartate channel by extracellular $\mathrm{H}^{+}$. Proc Natl Acad Sci USA 87: 6445-6449.

Tombaugh GC, Sapolsky RM (1990a) Mechanistic distinctions between excitotoxic and acidotic hippocampal damage in an in vitro model of ischemia. J Cereb Blood Flow Metab 10:527-535.

Tombaugh GC, Sapolsky RM (1990b) Mild acidosis protects hippocampal neurons from injury induced by oxygen and glucose deprivation. Brain Res 506:343-345.

Uematsu D, Greenberg JH, Hickey WF, Reivich M (1989) Nimodipine attenuates both increases in cytosolic free calcium and histologic damage following focal cerebral ischemia and reperfusion in cats. Stroke 20:1531-1537.

Voorhies TM, Rawlinson D, Vannucci RC (1986) Glucose and perinatal hypoxic-ischemic brain damage in the rat. Neurology 36:11151118.

Welsh FA, Ginsberg MD, Rieder W, Budd WW (1980) Deleterious effect of glucose pretreatment on recovery from diffuse cerebral ischemia in the cat. Stroke 11:355-363.

Yu AC, Gregory GA, Chan PH (1989) Hypoxia-induced dysfunctions and injury of astrocytes in primary cell cultures. J Cereb Blood Flow Metab 9:20-28. 